Chapter 25

\title{
Quantitative Evaluation of Completion Techniques on Influencing Shale Fracture 'Complexity'
}

\author{
N. Nagel, F. Zhang, M. Sanchez-Nagel and B. Lee \\ Additional information is available at the end of the chapter \\ http://dx.doi.org/10.5772/56304
}

\begin{abstract}
In many of the active shale plays, the extremely low permeability of the shale means simple, bi-planar hydraulic fractures do not provide enough surface area to make an economic well. In these cases, the optimal, economic completion requires stimulation of the natural fracture system - often called increasing the 'complexity' of the stimulation. A number of different multi-well completion techniques have been proposed to enhance shale complexity. The 'simul-frac' technique is where companion wells are stimulated at the same location at the same time, whereas the 'zipper-frac' technique employs companion wells that are stimulated in staggered locations at the same time. The intention with these techniques is to alter either or both the stress field and the pore pressure field to enhance the shearing of natural fractures.

In this paper, we present the results of a numerical study to quantitatively evaluate the effectiveness of multi-well completion techniques, particularly the 'modified zipper-frac' technique, to optimize shale completions. The study includes a parametric study of the effects of in-situ stress conditions, natural fracture orientation and fracture friction, and hydraulic fracture layout on changing near and far-field natural fracture shear (complexity). Changes in the stress field, particularly shear stress, are considered the primary means of increasing fracture complexity. The quantitative results of the study provide a means to optimize the application and design of different multi-well completion techniques as a function of the presented parameters. Optimized completion designs mean lower well costs, greater production and, ultimately, improved well economics.
\end{abstract}

Keywords: Hydraulic fracturing, stimulation, unconventional, complexity, well completion, shale, numerical simulation, simul-frac, zipper-frac, discrete element model, DEM, microseismicity 


\section{Introduction}

Much has now been written about the boom in shale gas and shale oil developments in the United States and around the world. In its recent assessment for example, the Energy Information Agency (EIA 2012) noted that North Dakota has become the second largest oil producer in the United States due to production from the Bakken shale. In addition, the EIA (EIA 2013) has predicted that the United States will continue to add more than 230,000 bpd of oil production per year through the end of the decade and become a net exporter of natural gas within the decade. Expenditures on shale gas and shale oil developments have also rapidly increased. For example, more than $\$ 54$ billion dollars was spend in drilling and development operations in the seven major US shale developments in 2012 (Clover Global Solutions 2012), with the bulk being spent in the Eagle Ford and Bakken plays.

Shale developments, notably beginning in the Barnett in the 1990s, have been driven by: 1) the application of horizontal wells; 2) the application and improvements in hydraulic fracturing; and 3) significant commodity prices (GWPC 2009 and King 2010). Because of the low permeability in most shale developments (nano-darcy permeability in shale gas plays and microdarcies in shale oil plays), hydraulic fracturing is a key technology because, as noted by King (2010), the presence of, and the ability to open and maintain flow in, both the primary and secondary natural fracture systems is critical. King further noted the importance of maximizing the fracture-to-shale contact area and optimizing the development, placement, and length of small fractures to enhance and stabilize well production (i.e., optimizing the stimulation of the natural fracture system - that is, increasing natural fracture 'complexity').

Because the stimulation of the natural fracture system is critical to many shale developments, a number of different multi-well completion schemes have been devised in an effort to improve the ability to enhance the stimulation of natural fractures. Three of the common completions schemes are shown in Figure 1. In simultaneous fracturing (plot A in Figure 1), the concept is that hydraulic fracturing both wells at the same time enhances the stimulation of the natural fractures. In the sequential (zipper) frac concept (plot B), the residual stress field from well \#1 is thought to enhance the stimulation of the natural fractures when well \#2 is stimulated. Finally, in the modified zipper-frac concept (plot C, Figure 1), the sequential stimulation of offsetting stages is thought to enhance the stimulation of the natural fractures.

\subsection{Natural fracture behavior}

A critical component to understanding the efficacy of multi-well completion techniques on increasing shale complexity is the understanding of the geomechanical behavior of natural fractures. The authors have written extensively about the mechanical behavior of natural fractures and the results of numerical modeling (both continuum and distinct element modeling) of the response of natural fractures to hydraulic fracture stimulation (Nagel et al. 2012a, Nagel et al. 2012b, Nagel et al. 2012c, Nagel et al. 2011a, Nagel et al. 2011b, and Nagel and Sanchez-Nagel 2011). Of first interest in evaluating the impact of multi-well completion schemes on the stimulation of natural fractures is the basic behavior of natural fracture shear and deformation. 
A

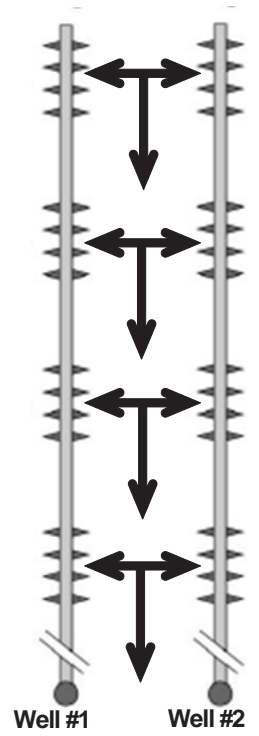

B

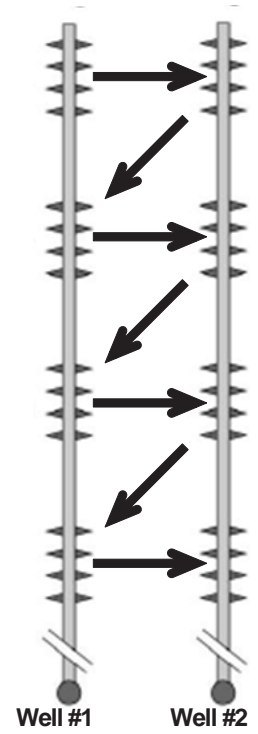

C

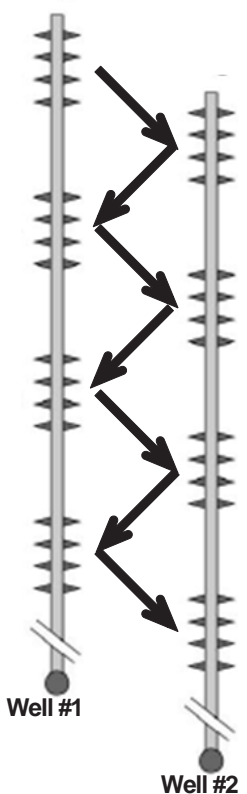

Figure 1. Common shale completion schemes. A) Simultaneous hydraulic fracturing; B) Sequential fracturing (zipperfrac); and C) Modified zipper-frac.

Nagel et al. (2012c) summarized five 'conditions' for natural fracture shear to occur:

1. The shear stress along the fracture grows to exceed the shear strength with no change in fracture friction, fracture normal stress, or fracture pore pressure;

2. Due to thermal or chemical changes, fracture friction is reduced while the shear stress along the fracture is unchanged and the fracture normal stress and fracture pore pressure are unchanged;

3. The fracture normal stress decreases with no change in the shear stress along the fracture, the fracture friction coefficient, or fracture pore pressure;

4. The fracture pore pressure increases with no change in the shear stress along the fracture, the fracture friction coefficient, or fracture normal stress; and

5. A variety of combinations of the above.

Of these, conditions 3 and 4 (and, by default, condition 5) are believed to be most relevant to the behavior of fractured shale plays during hydraulic fracturing. The impact of these conditions is shown graphically in Figure 2. Figure 2 is a schematic representation of the results of a direct shear test on a fractured rock sample. The $\mathrm{x}$-axis represents the shear displacement along the fracture during the test, and the y-axis represents the shear stress imparted to the 
rock in order to achieve the given displacement. Four stress-displacement profiles are shown, which represent increasing effective normal stress on the fracture. As the effective normal stress is increased, both the peak shear stress necessary to initiate non-elastic displacements and the shear stress necessary to continue non-elastic displacements increase.

The implications of this behavior are critical to understanding the behavior of natural fractures during hydraulic fracturing. As shown in Figure 2, as the normal stress acting on natural fractures increases (due, for example, to the inflation of an induced hydraulic fracture), greater shear stress is required to cause shear slippage and displacement along a natural fracture. Effectively, increasing the normal stress stabilizes the natural fractures. At the same time, as pressure increases within a natural fracture (due, for example, to bulk fluid flow into the natural fractures or pressure diffusion from the induced hydraulic fracture), less shear stress is required to cause shear slippage. Given this behavior for natural fractures, and the goal of increasing the shear stimulation of these during hydraulic fracturing, the evaluation of the impact of completion scheme on well stimulation should focus on whether or not the completion scheme increases the shear of the natural fractures.

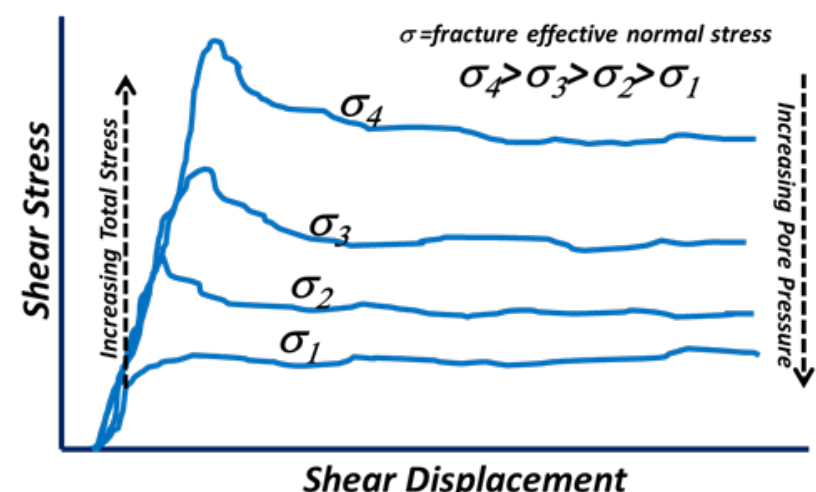

Figure 2. Shear-displacement profiles as a function of normal effective stress from direct shear testing of fractured rock.

\subsection{Hydraulic fracturing and stress shadows}

If increasing normal stress stabilizes natural fractures, then evaluating the stress changes from a hydraulic fracture is a required element of evaluations to optimize shale complexity. As far back as Sneddon's work on the evaluation of stress near a crack (Sneddon 1946), numerous authors have looked at the impact of stress field changes around hydraulic fractures (Nagel and Sanchez-Nagel 2011 and Warpinski et al. 2012). The stress field change, principally the increase in the minimum horizontal stress, Shmin, caused by a hydraulic fracture (typically the final, propped hydraulic fracture) is called the stress shadow effect or simply the stress 
shadow. Figure 3 shows the stress shadow (increase in Shmin) from a single hydraulic fracture that was $300 \mathrm{~m}$ long and $140 \mathrm{~m}$ in height (along the $\mathrm{x}-\mathrm{z}$ plane on the right side of the model) in a model that is $1000 \mathrm{~m}$ cube.

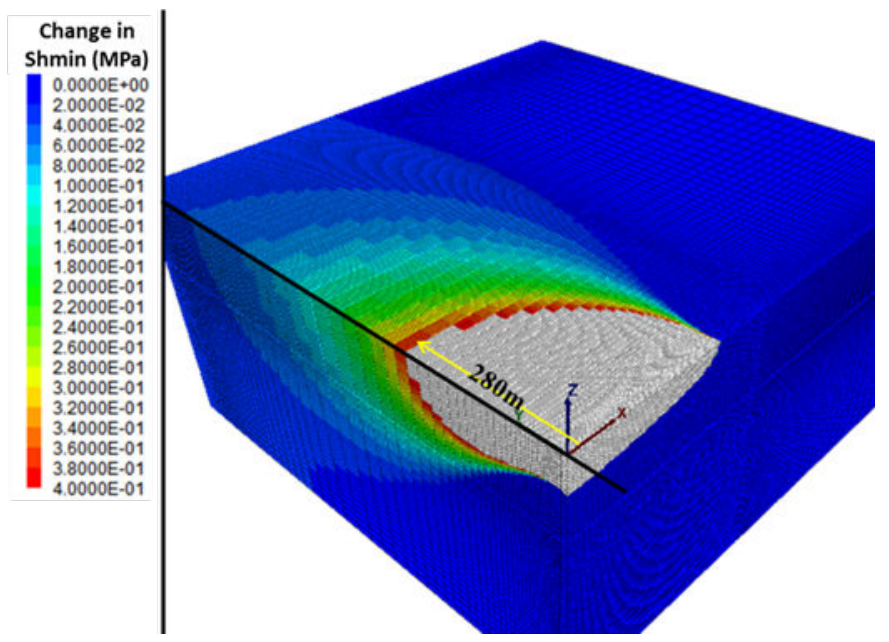

Figure 3. Stress shadow contours from a single $300 \mathrm{~m}$ long/140m high hydraulic fracture with a $5 \mathrm{MPa}$ net pressure applied on the $x-z$ plane. The cut-away image was created by cutting along the $y-z$ and $x-y$ planes. The model shown is $1000 \mathrm{~m}$ in each of the $\mathrm{x}$ and $\mathrm{y}$-directions. The white area is a region of stress change greater than the color scale shown (from Nagel et al. 2013).

As shown, note both the long distance over which the stress change occurs - to the edge of the $1000 \mathrm{~m}$ long block simulated - and the vertical spreading with distance. At large distances, the change in stress is seen to affect a total formation height more than double the original height of the created fracture. Note also the near-complete lack of stress change beyond the horizontal tip of the hydraulic fracture. Overall, the following can be summarized about stress shadows (Nagel and Sanchez-Nagel 2011):

- The increase in Shmin (stress shadow) extends significant distances behind a fracture and spreads out above and below the fracture but not beyond the tip of the fracture.

- The increase in Shmin due to a hydraulic fracture is largely unaffected by either the in-situ rock mechanical properties or the stress ratio (though these do appear to affect changes in the vertical stress and the SHmax stress).

- A horizontal shear stress field occurs with the fracture tip and does not extend back to the wellbore. This suggests that, at some distance behind the fracture tip, the effect of the stress shadow is to stabilize the natural fracture system. 
- Reducing fracture spacing results in a greater minimum Shmin stress increase in the interfracture region as the stress shadows from each fracture overlap more with reduced fracture spacing.

\subsection{Natural fracture behavior and stress shadows: Implications for completion strategies}

The combined consideration of the basic mechanical behavior of natural fractures and the nature of stress shadows suggests the following for a multi-well completion strategy:

- The stress shadow effect, that is the increase in the principal stresses around a hydraulic fracture, causes a stabilization of natural fractures. This can only be overcome by increasing the fluid pressure within the natural fractures (suggesting a desire to increase the net pressure, which would also increase the stress shadow). Decreasing stage spacing, or overlapping hydraulic fractures from different wells, will tend to increase the stress shadow effect and impair the stimulation of natural fractures.

- Because the stress shadow effect does not extend horizontally beyond the tip of the hydraulic fracture (the x-direction in Figure 3), when two fractures are simultaneous created from parallel wellbores, the fractures will not 'see' each other until the tip regions are very near to each other (and increase the potential for screenout during a stimulation).

\subsection{Numerical simulation of completion strategies: Modified zipper-frac}

In this paper, numerical simulation results are presented for the evaluation of the modified zipper-frac multi-well completion strategy. The simulations were conducted with a 2D discrete element model (DEM) under different well configurations for two different natural fracture networks, different fracture friction angles, and different stress ratio conditions.

\section{Model setup and simulation matrix}

\subsection{D DEM model capabilities}

A two-dimensional DEM code was used in all the simulations presented. The code used was a general-purpose program based on the distinct element method for discontinuum modeling. The code can simulate the response of discontinuous media (such as a jointed rock mass) subjected to either static or dynamic loading. The discontinuous medium is represented as an assemblage of discrete blocks, and discontinuities are treated as boundary conditions between blocks. Large displacements along discontinuities and rotations of blocks are allowed. Individual blocks behave as either rigid or deformable material. Deformable blocks are subdivided into a mesh of finite-difference elements, and each element responds according to a prescribed linear or nonlinear stress-strain law. The relative motion of the discontinuities is also governed by linear or nonlinear force-displacement relations for movement in both the normal and shear directions. The basic formulation of the code assumes a two-dimensional plane-strain state. This condition is associated with long structures or excavations with a 
constant cross-section acted on by loads in the plane of the cross section. Discontinuities, therefore, are considered as planar features oriented normal to the plane of analysis. For planestrain analyses, blocks may exhibit plastic yield, and failure can occur in the out-of-plane direction if the out-of-plane stress becomes a major or minor principal stress.

The critical modeling features for the simulation of hydraulic fracturing include:

- A rock mass is modeled as an assemblage of rigid or deformable blocks. The size, shape, and orientation of the blocks are defined by the imported Discrete Fracture Network (DFN) or by the internal fracture generator.

- Discontinuities are regarded as distinct boundary interactions between blocks, and continuous and discontinuous joint patterns or joint properties can be generated on a statistical basis or from an imported DFN.

- Fractures are created within, and propagate along, the static block boundary planes; however, propagation can be modeled explicitly based upon the stress intensity factor at the fracture tip. Fracture behavior is prescribed by the block interactions. Thus, natural fracture aperture is, for example, affected by shear displacement and fracture fluid pressure.

- Fluid flow is limited to flow within the fractures, and matrix fluid (and, for example, fluid leakoff) is not considered.

\subsection{Model setup}

Figure 4 shows the setup and dimensions of the 2D model in planview at the centerline of the horizontal wellbores (located along the left and right sides of the model shown). Table 1 summarizes the model mechanical parameters while Table 2 summarizes the stress conditions used. The total model was $1200 \mathrm{~m}$ long in the direction of Shmin (vertical or y-direction) and $225 \mathrm{~m}$ wide in the direction of SHmax (horizontal or x-direction) as shown in plot A of Figure 4. In order to avoid boundary effects, the vertical boundaries were placed at a large distance (> 550m) from the simulated hydraulic fractures and roller boundaries were applied. The horizontal boundaries were considered to be symmetry planes at the wellbore locations (as only half the fracture length was modelled) and roller boundaries were also applied.

Two different natural fracture patterns were employed. In plot B of Figure 4 (note that plot B and $C$ represent the central core in green from plot A), the ' $180^{\circ}$ ' fracture pattern is shown. This pattern contains two fracture sets, which are nominally orthogonal to each other and aligned with the principal stress directions. The second fracture pattern, called the ' $145^{\circ}$ ' pattern, is shown in plot C. For the $145^{\circ}$ pattern, the same two fracture sets from the $180^{\circ}$ pattern have been rotated roughly $45^{\circ}$ relative to the principal stresses.

The simulated hydraulic fractures are shown in solid and dashed black lines in plots B and C. The solid line represents the first hydraulic fracture location (Xf1) and the dashed lines represent the location of the second hydraulic fracture $(X f 2)$ at a distance of $20 \mathrm{~m}, 35 \mathrm{~m}$, and $45 \mathrm{~m}$ offset along the wellbore from Xf1. When fully propagated, Xf1 and Xf2 were $125 \mathrm{~m}$ long (their fracture half length). 
A

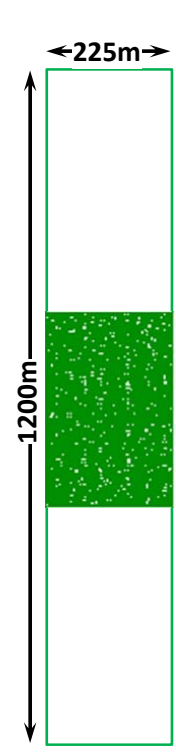

B

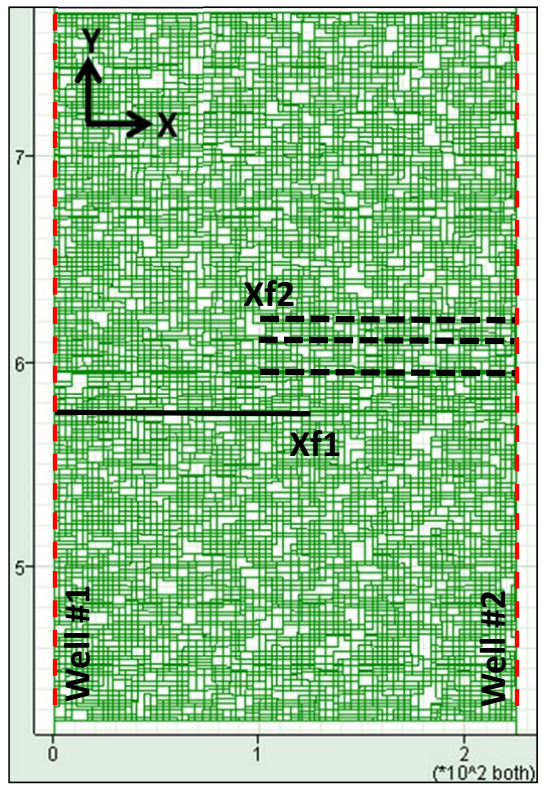

C

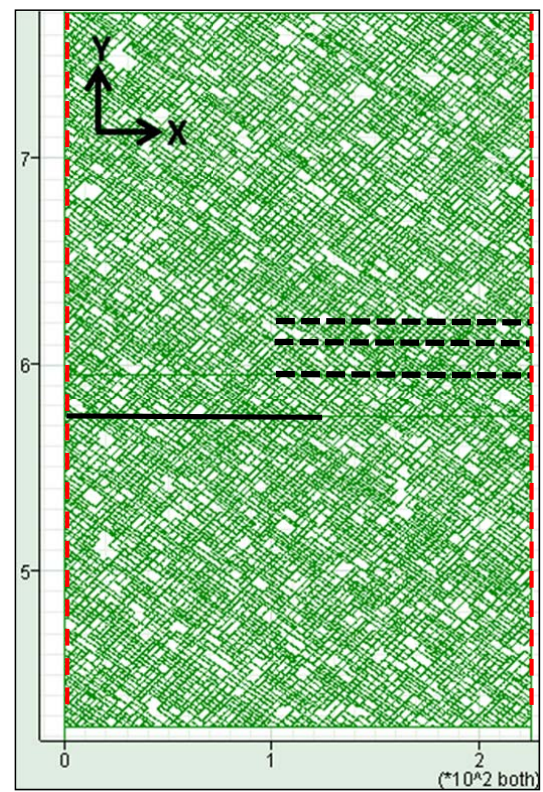

Figure 4. DEM model setup and dimensions. A) Full model - only the middle section in green contained fractures; B) Middle section natural fracture pattern for the ' $180^{\circ}$ ' model; and C) Middle section natural fracture pattern for the ' $145^{\circ \prime}$ model. The location of simulated hydraulic fractures are represented by the black lines. Horizontal wellbores are located along the full length of the left and right sides of the model.

\begin{tabular}{ccc}
\hline & DFN \#1 & DFN \#2 \\
\hline Case Name & $' 180^{\circ \prime}$ & $' 145^{\circ \prime}$ \\
\hline Matrix Young's modulus & $27.6 \mathrm{GPa}$ & $27.6 \mathrm{GPa}$ \\
\hline Matrix Poisson's ratio & 0.25 & 0.25 \\
\hline Fracture Set \#1 Orientation & $\mathrm{N} 180^{\circ}$ & $\mathrm{N} 145^{\circ}$ \\
\hline Set\#1 Trace Length, mean & $35 \mathrm{~m}$ & $35 \mathrm{~m}$ \\
\hline Set\#1 Trace Length, st. deviation & $10 \mathrm{~m}$ & $10 \mathrm{~m}$ \\
\hline Set\#1 Gap Length & $5 \mathrm{~m}$ & $5 \mathrm{~m}$ \\
\hline Set\#1 Spacing, mean & $2 \mathrm{~m}$ & $2 \mathrm{~m}$ \\
\hline Set\#1 Spacing, st. deviation & $0.75 \mathrm{~m}$ & $0.75 \mathrm{~m}$ \\
\hline Fracture Set \#2 Orientation & $\mathrm{N} 90^{\circ}$ & $\mathrm{N45}$ \\
\hline Set\#2 Trace Length, mean & $35 \mathrm{~m}$ & $35 \mathrm{~m}$ \\
\hline Set\#2 Trace Length, st. deviation & $10 \mathrm{~m}$ & $10 \mathrm{~m}$ \\
\hline
\end{tabular}




\begin{tabular}{ccc}
\hline & DFN \#1 & DFN \#2 \\
\hline Set\#2 Gap Length & $5 \mathrm{~m}$ & $5 \mathrm{~m}$ \\
\hline Set\#2 Spacing, mean & $3 \mathrm{~m}$ & $3 \mathrm{~m}$ \\
\hline Set\#2 Spacing, st. deviation & $1 \mathrm{~m}$ & $1 \mathrm{~m}$ \\
\hline Fracture Normal Stiffness & $2 \mathrm{e} 11 \mathrm{~Pa}$ & $2 \mathrm{e} 11 \mathrm{~Pa}$ \\
\hline Fracture Shear Stiffness & $2 \mathrm{e} 11 \mathrm{~Pa}$ & $2 \mathrm{e} 11 \mathrm{~Pa}$ \\
\hline Initial Fracture Aperture & $0.1 \mathrm{~mm}$ & $0.1 \mathrm{~mm}$ \\
\hline
\end{tabular}

Table 1. Mechanical Parameters Used For Model Construction

\begin{tabular}{|c|c|c|c|}
\hline & \multicolumn{2}{|c|}{ DFN \#1 } & DFN \#2 \\
\hline Case Name & \multicolumn{2}{|c|}{$' 180^{\circ}$} & $145^{\circ \prime}$ \\
\hline Vertical Stress, Sv & $55.2 \mathrm{MPa}$ & $55.2 \mathrm{MPa}$ & $55.2 \mathrm{MPa}$ \\
\hline Max. Horizontal Stress, SHmax & $44.8 \mathrm{MPa}$ & $44.8 \mathrm{MPa}$ & $44.8 \mathrm{MPa}$ \\
\hline Min. Horizontal Stress, Shmin & $37.9 \mathrm{MPa}$ & $43.5 \mathrm{MPa}$ & $37.9 \mathrm{MPa}$ \\
\hline Pore Pressure & $27.6 \mathrm{MPa}$ & $27.6 \mathrm{MPa}$ & $27.6 \mathrm{MPa}$ \\
\hline
\end{tabular}

Table 2. Model Stress And Pore Pressure Data

\subsection{Modeling assumptions}

For any numerical modeling, assumptions need to be made for the problem being simulated. For the simulations described in this paper, the following assumptions were made:

- 2D, plane strain condition exists (i.e., effects above and below the vertical centerline of a vertical hydraulic fracture do not impact the results).

- Hydraulic fracturing is a quasi-static process and both fracture propagation and injection rate effects can be ignored for the cases being simulated (i.e., the hydraulic fracturing process can be represented by static simulations of the fracture at specific lengths under a given net pressure).

- Events within the formation at the tip of the hydraulic fracture can be simulated without fluid flow within the natural fractures (i.e., the behavior within the formation at the tip is dominated by the changes in total stress and pore pressure changes are negligible).

- Net injection pressure was a constant $4 \mathrm{MPa}$ within the hydraulic fractures Xf1 and Xf2 for all simulations.

- Simulations were conducted first for single hydraulic fractures (without influence from a second, nearby hydraulic fracture). Then simulations were conducted for dual hydraulic fractures and compared to results from two hydraulic fractures acting independent of each other. 


\subsection{Simulation matrix}

In total, nearly 100 simulations were performed in order to explore the behavior of the modified zipper-frac completion scheme. 20 simulations were performed to look at the shear results from a single hydraulic fracture with the ' $180^{\circ}$ ' (DFN\#1 from Tables 1 and 2 ) varying the length of both fractures Xf1 and Xf2 separately (Xf1 represents the left-side hydraulic fracture - the solid black line in Figure 4 - and Xf2 represents the right-side hydraulic fracture - the dashed lines in Figure 4) from $25 \mathrm{~m}$ to $125 \mathrm{~m}$ in $25 \mathrm{~m}$ increments with a friction angle of 15 degrees (10 simulations) and repeating these with a 25 degree friction angle (10 simulations). Then 60 simulations were performed to look at the efficacy of the modified zipper-frac completion by performing simulations with dual hydraulic fractures with both DFN models (the ' $180^{\circ}$ ' and ' $\left.145^{\circ \prime}\right)$ varying the length of Xf2 $(0 \mathrm{~m}, 50,75 \mathrm{~m}, 100 \mathrm{~m}$, and $125 \mathrm{~m})$ for a constant Xf1 of $125 \mathrm{~m}$ length for three separation spacings $(20 \mathrm{~m}, 35$, and $45 \mathrm{~m}$, where separation is the horizontal offset of the Xf1 and Xf2 fractures as shown in Figure 4) and for two friction angles (15 degrees and 25 degrees in the ' $180^{\circ \prime}$ model and 25 degrees and 35 degrees in the ' $145^{\circ \prime}$ model). Finally, an additional 15 simulations were performed with the ' $180^{\circ}$ ' model varying the initial in-situ stress (see Table 2) and Xf2 length, and keeping the friction angle at 25 degrees.

\section{Quantitative numerical evaluation of modified zipper-fracs}

\subsection{Natural fracture shear from a single hydraulic fracture}

A first series of base case simulations were conducted in order to evaluate the natural fracture shear from a single fracture. The simulations looked at the growth of the Xf1 hydraulic fracture as well as the $\mathrm{Xf} 2$ hydraulic fracture for two different fracture friction angles. These base case simulations are important because, in order to correctly evaluate the benefit or detriment of the dual frac modified zipper-frac completion, the effect of the two fractures Xf1 and Xf2 completely independent of each other needs to be considered.

Figure 5 shows the natural fracture shear region (in blue) for both the $15^{\circ}$ (plot A) and the $25^{\circ}$ friction angle simulations for the ' $180^{\circ}$ ' DFN model when Xf1 had a fracture half-length of $100 \mathrm{~m}$. As an example, the total cumulative length of natural fractures at shear condition in plot A (the sum of the length of the natural fractures in blue in Figure 5) was $300.1 \mathrm{~m}$ versus $80.8 \mathrm{~m}$ in plot B. Figure 6 shows the combined shear for the five Xf1 length simulations and the combined sheared area (shaded area) for the propagation of Xf1 from the wellbore to a $125 \mathrm{~m}$ half-length. As expected, the area of shear for the lower friction simulations is considerably greater $\left(5740 \mathrm{~m}^{2}\right)$ than for the higher friction simulations $\left(2220 \mathrm{~m}^{2}\right)$.

The shaded area in Figure 6 and others, adjusted for the length of Xf2 in the dual fracture simulations, represents the sheared area for Xf2 when Xf2 was created independently of Xf1. This shaded area then allows for comparison of independent $\mathrm{Xf1}$ and $\mathrm{Xf} 2$ hydraulic fracture effects to modified zipper-frac effects. 


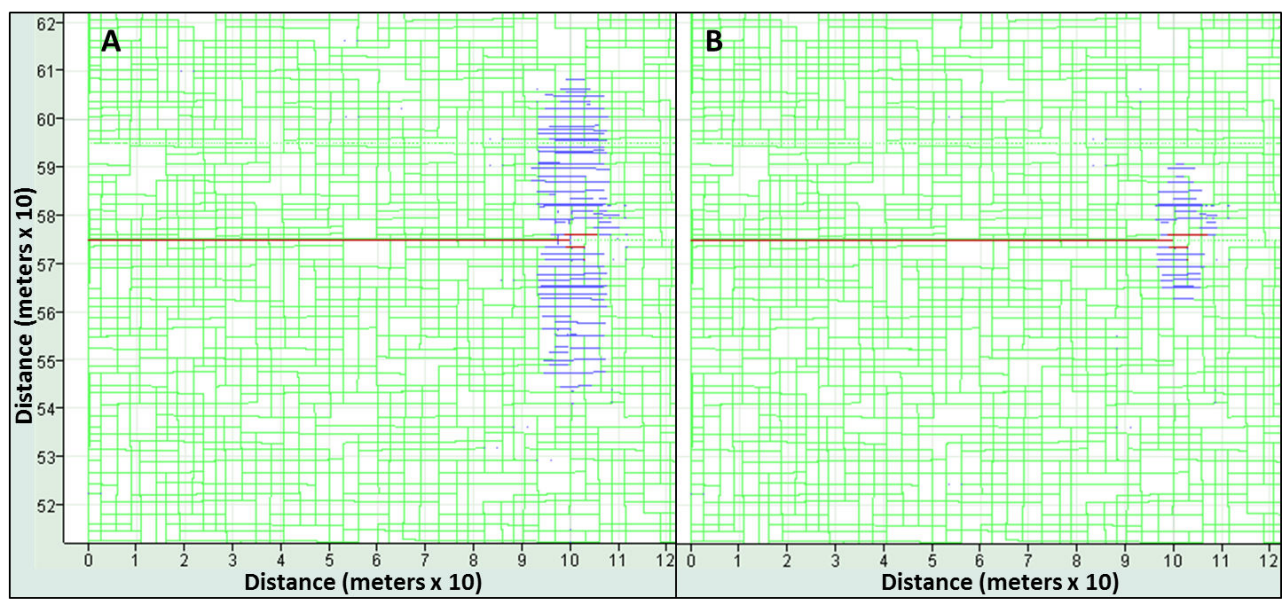

Figure 5. Natural fracture shear (blue lines) for a 100m-long Xf1 hydraulic fracture. A) Shear for the $15^{\circ}$ fracture friction case; and B) Shear for the $25^{\circ}$ fracture friction case.

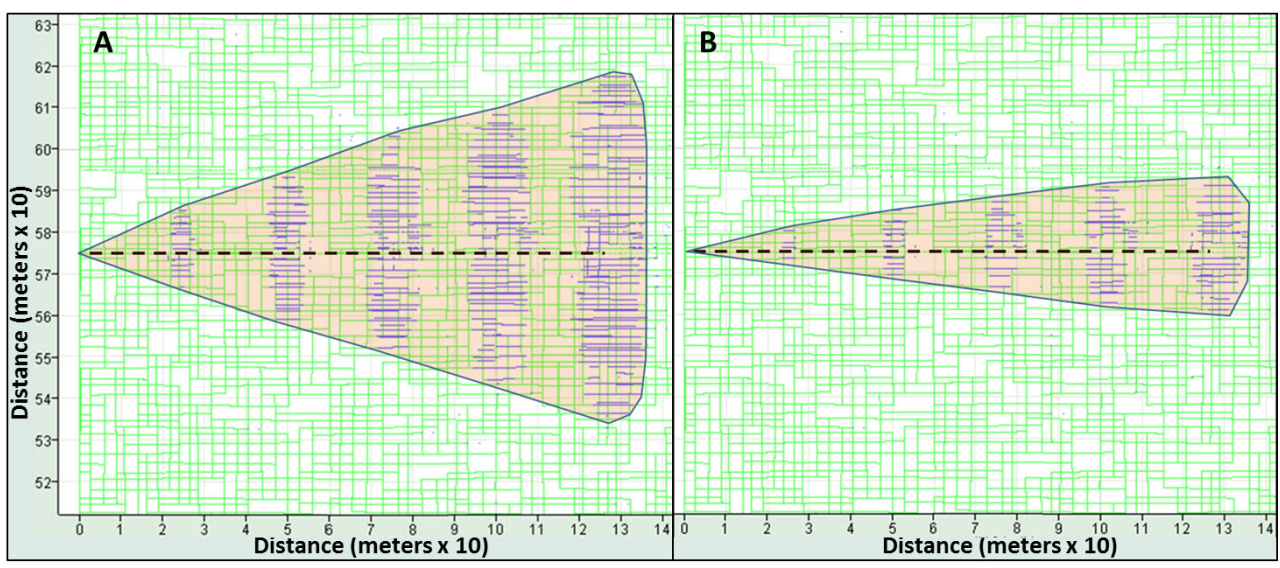

Figure 6. Cumulative natural fracture shear (shaded area) from simulations at 25 to $125 \mathrm{~m}$ hydraulic fracture half length. A) Shear for the $15^{\circ}$ friction case with an area of $5740 \mathrm{~m}^{2}$; and B) Shear for the $25^{\circ}$ friction case with an area of $2220 \mathrm{~m}^{2}$.

Figure 7 shows the growth of sheared natural fracture length as a function of hydraulic fracture half-length for the $15^{\circ}$ and $25^{\circ}$ natural fracture friction cases for all 20 single fracture simulations. Not surprisingly, given the slight variability in the statistics for natural fracture generation, there are slight, insignificant differences between the results for the Xf1 and Xf2 simulations. 


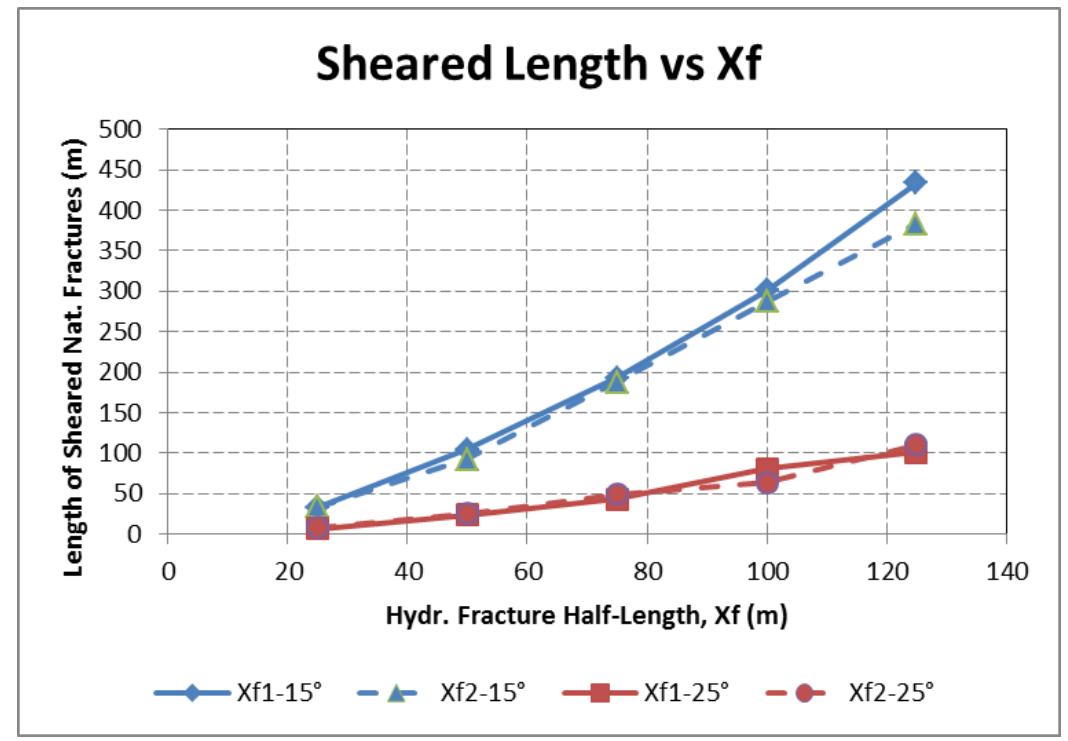

Figure 7. Cumulative natural fracture shear length versus hydraulic fracture half-length for single hydraulic fracture simulations.

A similar evaluation to Figure 6 was performed for the ' $145^{\circ}$ ' DFN case as shown in Figure 8. Note that in plot A, natural fracture friction was $25^{\circ}$ and in plot B natural fracture friction was $35^{\circ}$.

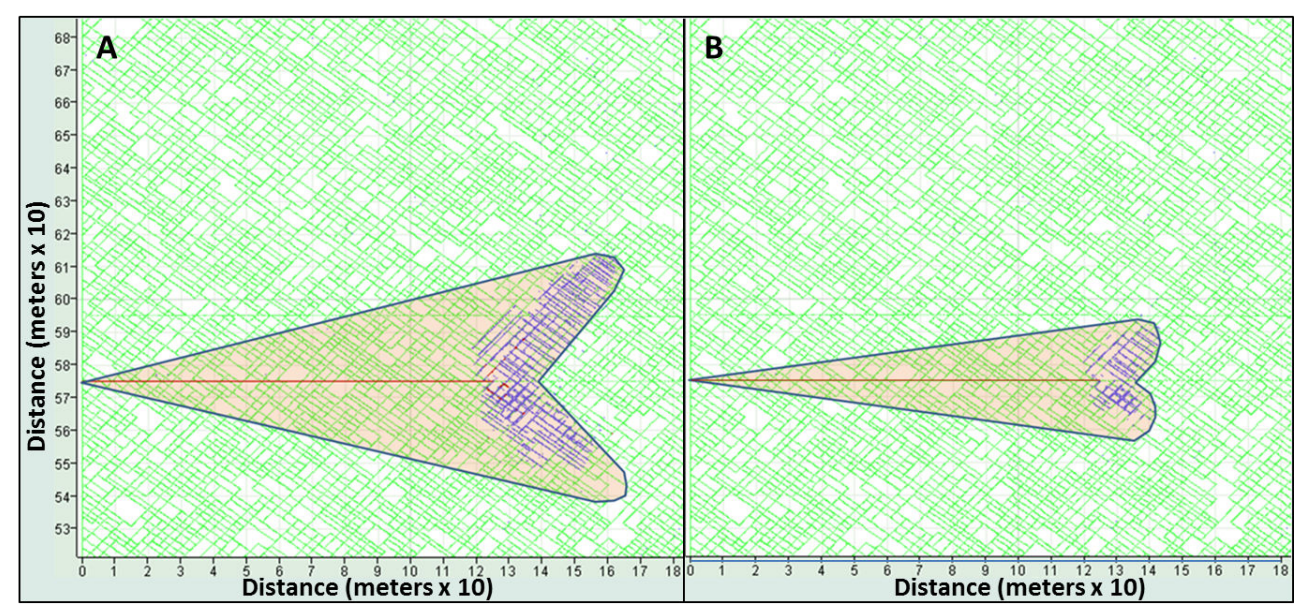

Figure 8. Cumulative natural fracture shear (shaded area) from simulations with the ' $145^{\circ \prime}$ DFN. A) Shear for the $25^{\circ}$ friction case with an area of $5250 \mathrm{~m} 2$; and B) Shear for the $35^{\circ}$ friction case with an area of $2490 \mathrm{~m} 2$. 
In summary, Figures 5 through 8 suggest the following:

- Natural fracture shear from the total stress change caused by the inflated hydraulic fracture travels with the tip of a growing hydraulic fracture (as reported in Nagel et al. 2011a and 2012a).

- The length of natural fractures being sheared increases significantly with length (Figure 7).

- The length of natural fractures being sheared is strongly a function of natural fracture friction angle.

- The area (and by default the volume) of formation sheared by a single fracture can also be significant $\left(5740 \mathrm{~m}^{2}\right.$ for the $15^{\circ}$ case and $2220 \mathrm{~m}^{2}$ for the $25^{\circ}$ case of the ' $180^{\circ \prime}$ DFN and $5250 \mathrm{~m}^{2}$ for the $25^{\circ}$ case and $2490 \mathrm{~m}^{2}$ for the $35^{\circ}$ case of the ' $145^{\circ \prime} \mathrm{DFN}$ ).

- The orientation of the natural fractures significantly affects natural fracture shear for a given fracture friction (at $25^{\circ}$ friction, more than twice the shear occurred for the ' $145^{\circ \prime}$ DFN as for the ' $180^{\circ}$ ' DFN).

\subsection{Natural fracture shear superimposing two hydraulic fractures}

Figures 9 through 12 show the superimposed natural fracture shear areas from independent hydraulic fractures for multi-well completions with hydraulic fracture separations ranging from zero (equivalent to either the simultaneous or zipper-fracs) to $45 \mathrm{~m}$ for both fracture friction cases.

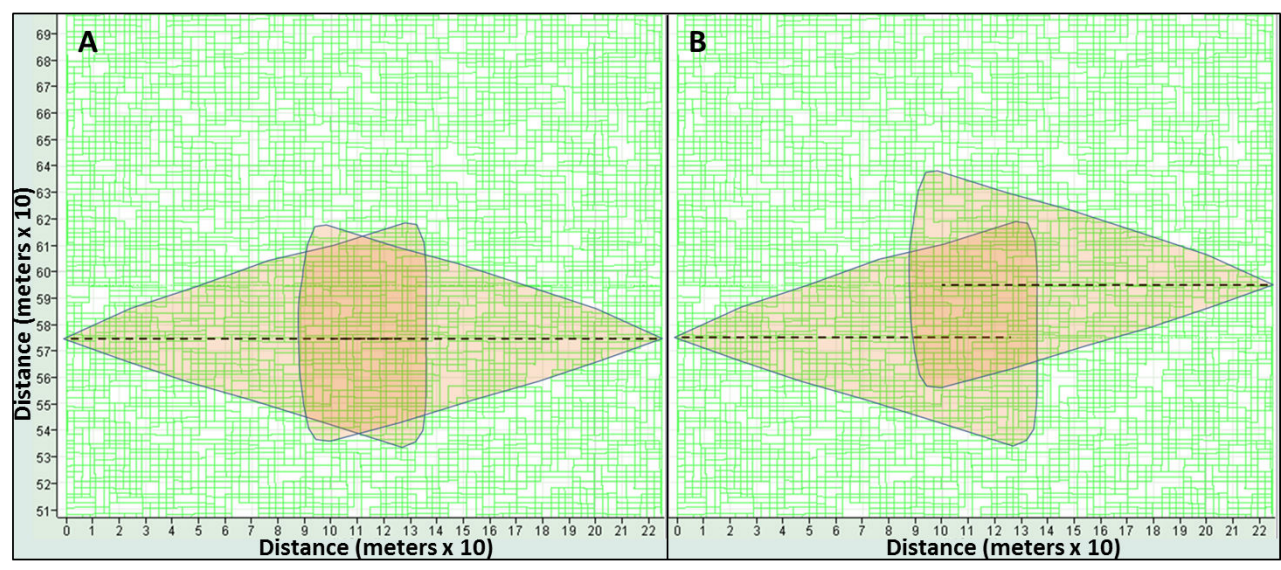

Figure 9. Superimposed natural fracture shear areas for the $15^{\circ}$ friction case when $\mathrm{Xf} 1$ and $\mathrm{Xf} 2$ are both $125 \mathrm{~m}$ in halflength. A) Zero separation between the two hydraulic fractures; and B) A $20 \mathrm{~m}$ separation between fractures.

Within the figures, the regions of overlap would likely represent areas of 'wasted' hydraulic fracture shear (and, perhaps, a negative effect on production as excess shear will cause the natural fractures to reclose and even fill with gouge). Ideally, the best effect, assuming no 
geomechanical interaction between the two hydraulic fractures, may be when the natural fracture shear regions just touch each other (not unlike the situation in Figure 12A).

Figures 9 and 10 suggest that overlapping the lengths of the hydraulic fracture (as proposed in the modified zipper-frac completion) creates large overlapping natural fracture shear areas for the $15^{\circ}$ fracture friction case. Further, increasing the hydraulic fracture separation out to $45 \mathrm{~m}$ still results in considerable overlap of the shear regions. In contrast, with the reduction in shear area due to the increase in natural fracture friction in the $25^{\circ}$ friction case in Figures 11 and 12 , the shear region overlap goes away at a $35 \mathrm{~m}$ hydraulic fracture spacing, and for the $45 \mathrm{~m}$ separation case an unsheared region (Figure 12, plot B) occurs between the hydraulic fractures.

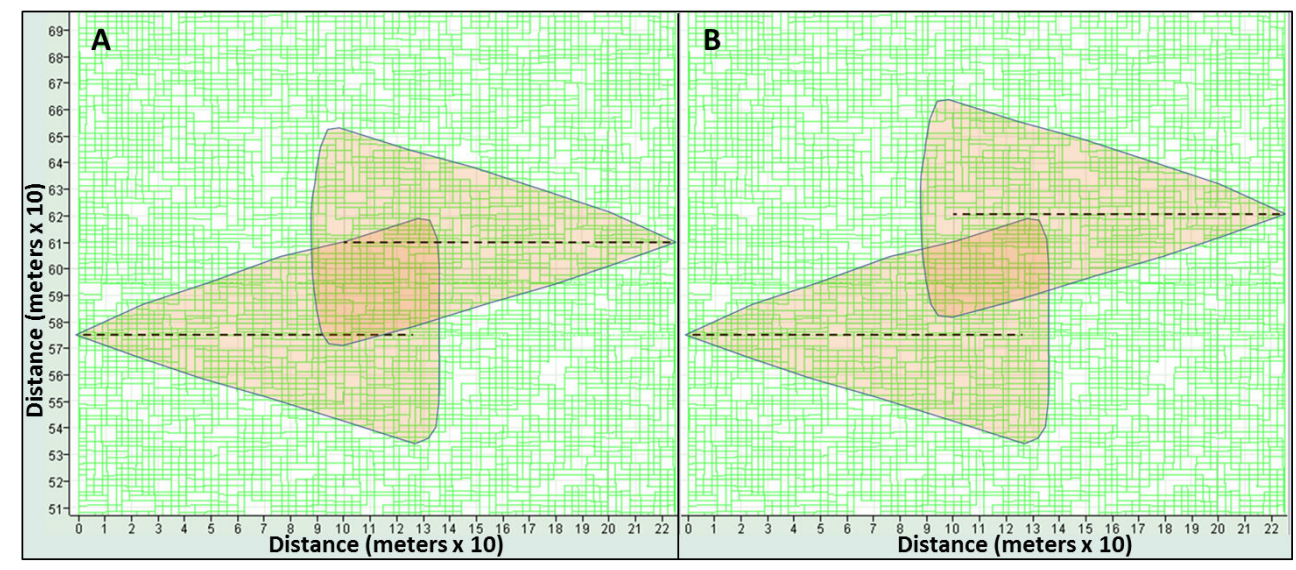

Figure 10. Superimposed natural fracture shear areas for the $15^{\circ}$ friction case when $X f 1$ and $X f 2$ are both $125 \mathrm{~m}$ in half-length. A) A $35 \mathrm{~m}$ separation between the two hydraulic fractures; and B) A 45m separation between fractures.

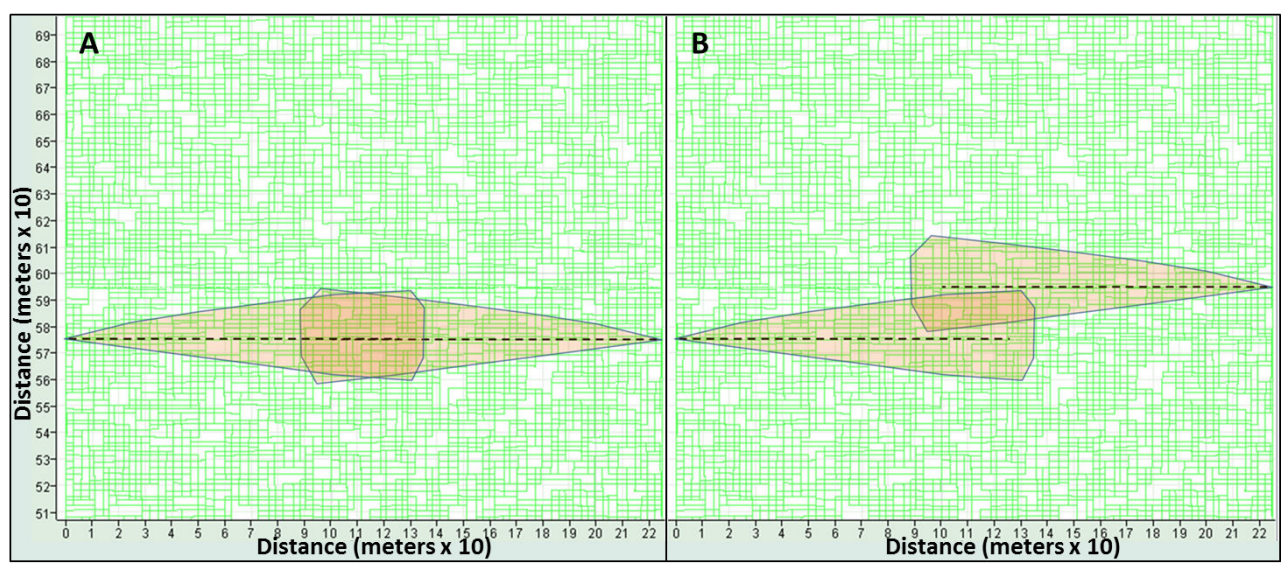

Figure 11. Superimposed natural fracture shear areas for the $25^{\circ}$ friction case when $X f 1$ and $X f 2$ are both $125 \mathrm{~m}$ in half-length. A) Zero separation between the two hydraulic fractures; and B) A $20 \mathrm{~m}$ separation between fractures. 


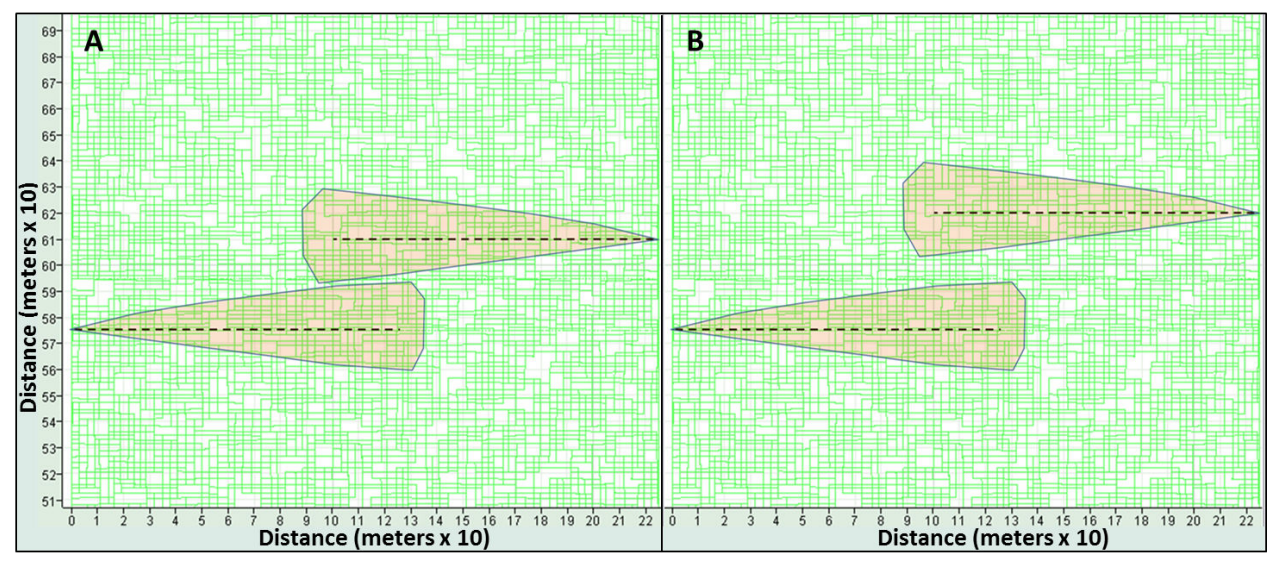

Figure 12. Superimposed natural fracture shear areas for the $25^{\circ}$ friction case when Xf1 and Xf2 are both $125 \mathrm{~m}$ in half-length. A) A $35 \mathrm{~m}$ separation between the two hydraulic fractures; and B) A $45 \mathrm{~m}$ separation between fractures.

\subsection{Natural fracture shear from dual, competing hydraulic fractures}

\subsubsection{Shear results for the ' $145^{\circ \prime} D F N$ and $20 m$ hydraulic fracture separation}

Figures 13 through 20 show the generation of natural fracture shear from combinations of the two hydraulic fractures $\mathrm{Xf} 1$ and $\mathrm{Xf} 2$ as a function of $\mathrm{Xf} 2$ length and natural fracture friction for the ' $145^{\circ}$ ' DFN with a hydraulic fracture separation of $20 \mathrm{~m}$. Plot A shows the sheared natural fractures in blue and open fractures in red; plot B shows the same data with an overlay of sheared natural fracture area (similar to Figure 8) as if hydraulic fractures Xf1 and Xf2 propagated independent of each other.

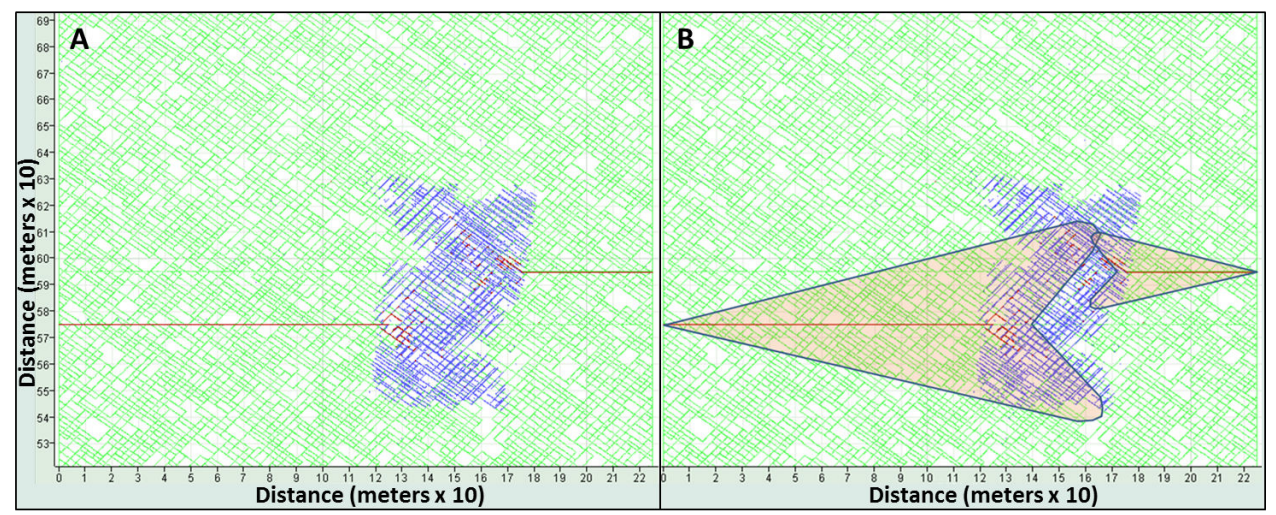

Figure 13. Natural fracture shear in blue from propagating hydraulic fractures $X f 1$ (from the left at $125 \mathrm{~m}$ ) and $\mathrm{Xf2}$ (from the right at $50 \mathrm{~m}$ ) for a natural fracture friction of $25^{\circ}$ and $20 \mathrm{~m}$ hydraulic fracture separation. Red represents open fractures. A) Shear and open fractures only; and B) Shear and open fractures with overlay of shear area as if Xf1 and $\mathrm{Xf} 2$ propagated independently. 


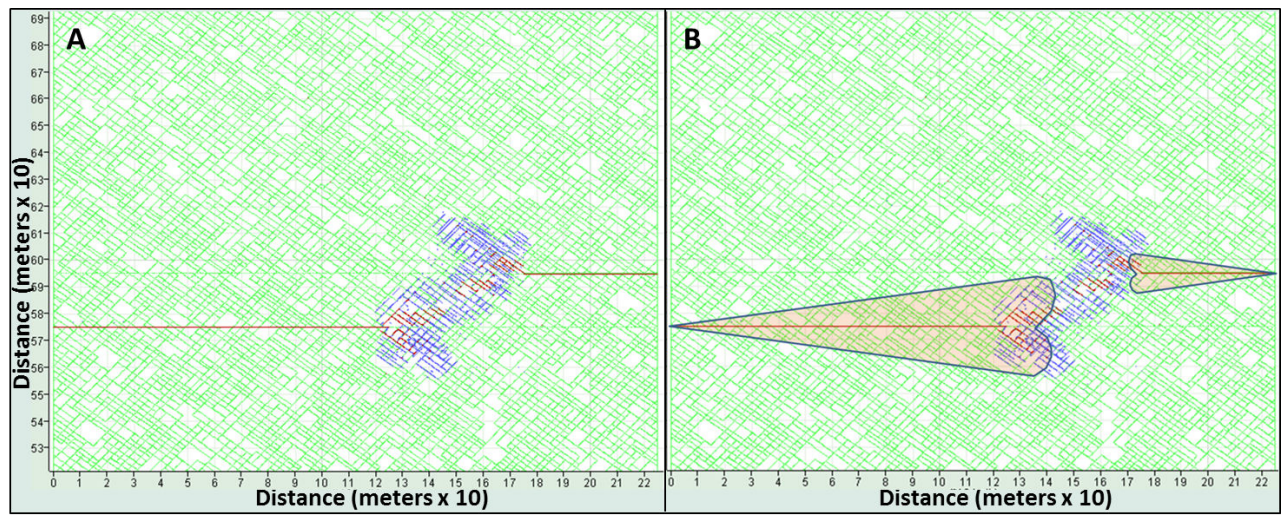

Figure 14. Natural fracture shear in blue from propagating hydraulic fractures $X f 1$ (from the left at $125 \mathrm{~m}$ ) and $X f 2$ (from the right at $50 \mathrm{~m}$ ) for a natural fracture friction of $35^{\circ}$.

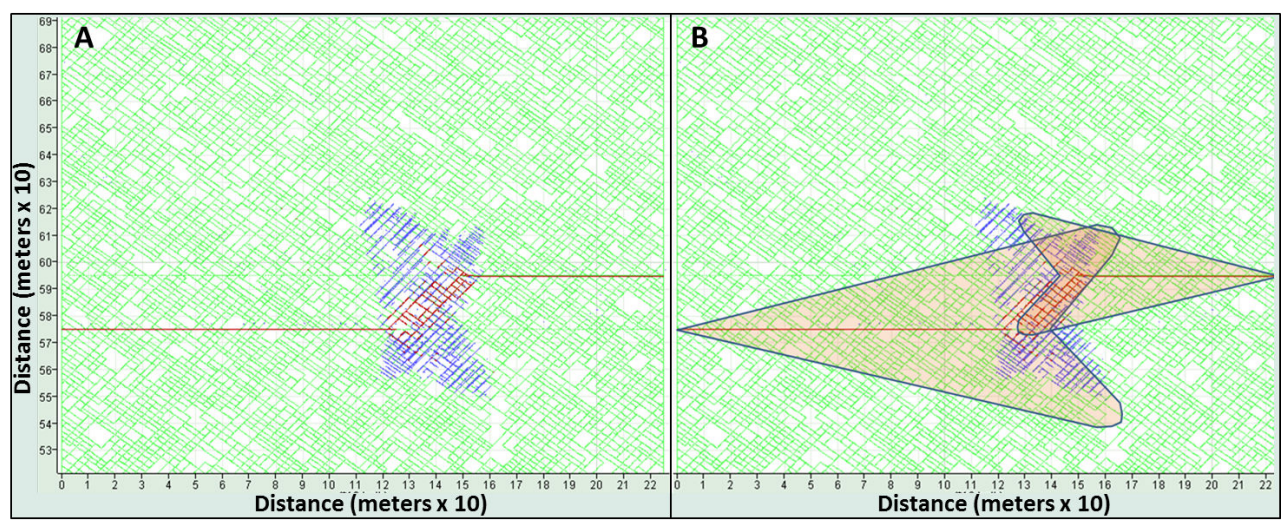

Figure 15. Natural fracture shear in blue from propagating hydraulic fractures $X f 1$ (from the left at $125 \mathrm{~m}$ ) and $X f 2$ (from the right at $75 \mathrm{~m}$ ) for a natural fracture friction of $25^{\circ}$. 


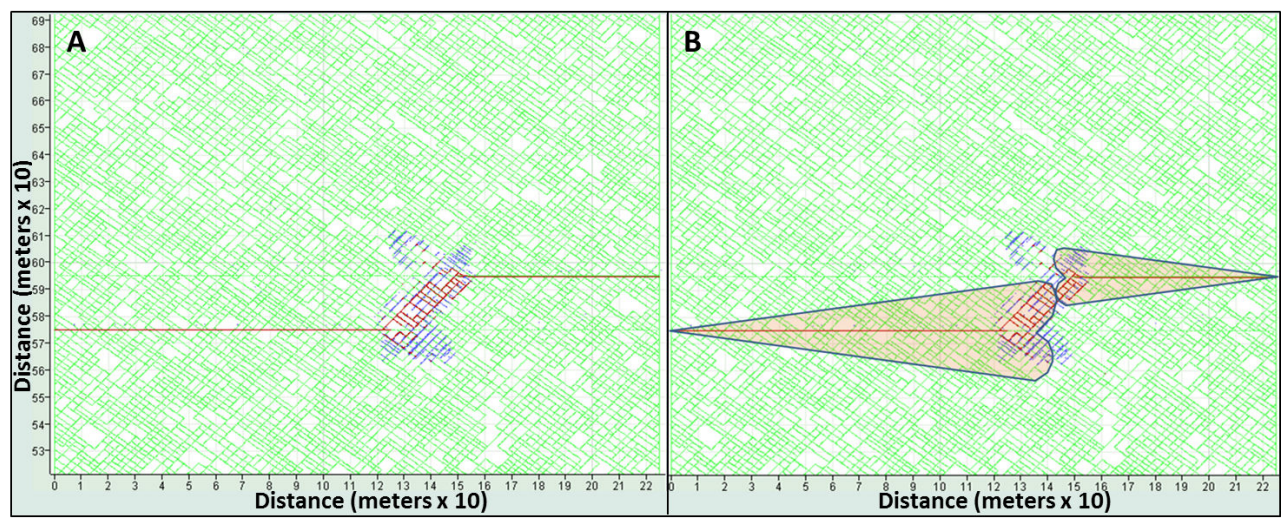

Figure 16. Natural fracture shear in blue from propagating hydraulic fractures $X f 1$ (from the left at $125 \mathrm{~m}$ ) and $X f 2$ (from the right at $75 \mathrm{~m}$ ) for a natural fracture friction of $35^{\circ}$.

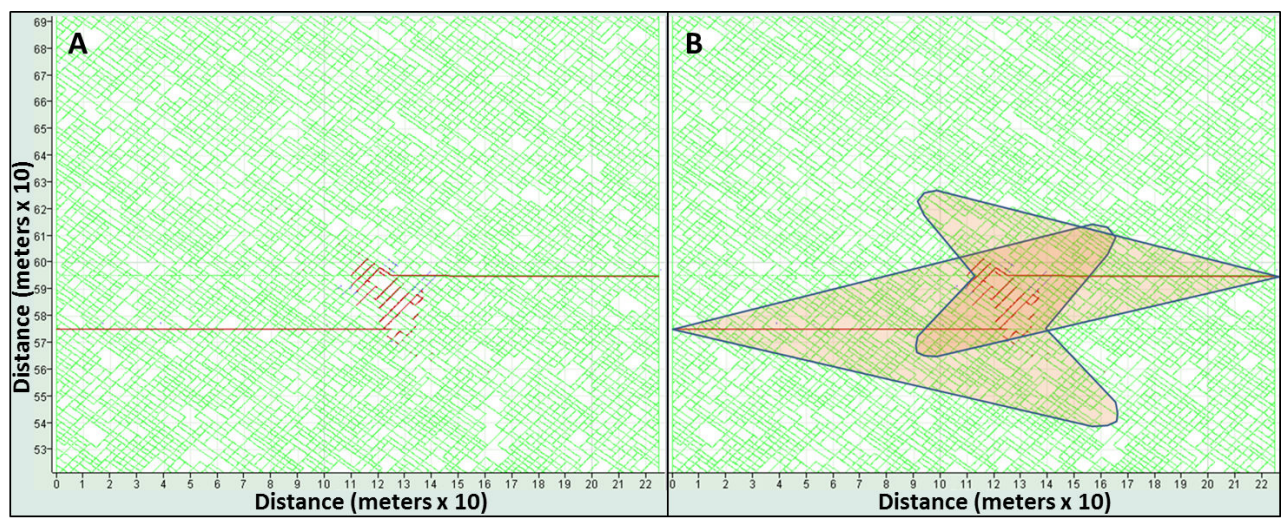

Figure 17. Natural fracture shear in blue from propagating hydraulic fractures $X f 1$ (from the left at $125 \mathrm{~m}$ ) and $X f 2$ (from the right at $100 \mathrm{~m}$ ) for a natural fracture friction of $25^{\circ}$. 


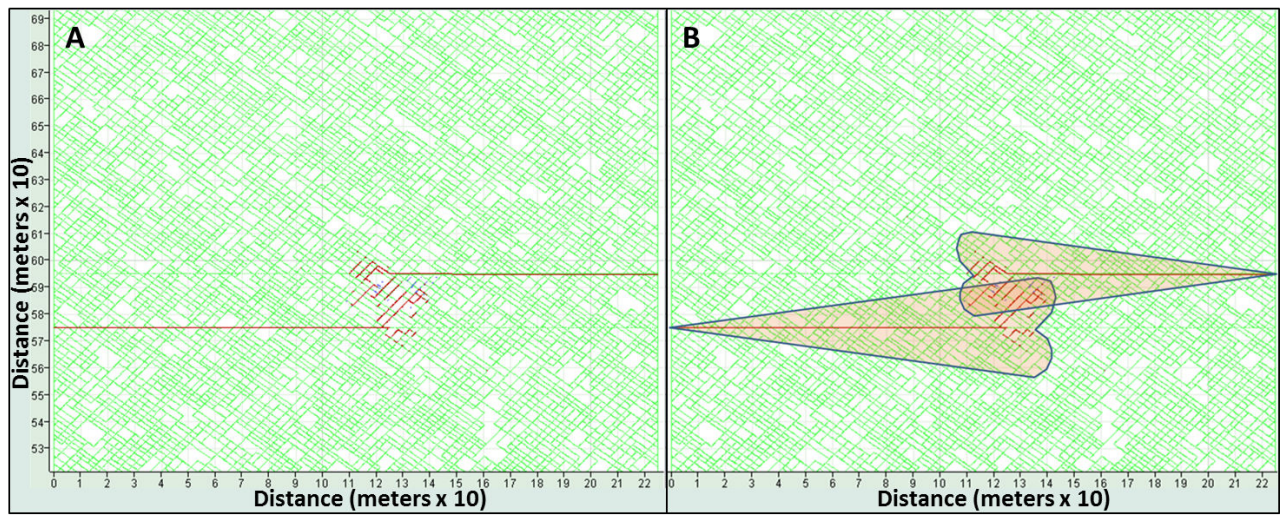

Figure 18. Natural fracture shear in blue from propagating hydraulic fractures Xf1 (from the left at $125 \mathrm{~m}$ ) and Xf2 (from the right at $100 \mathrm{~m}$ ) for a natural fracture friction of $35^{\circ}$.

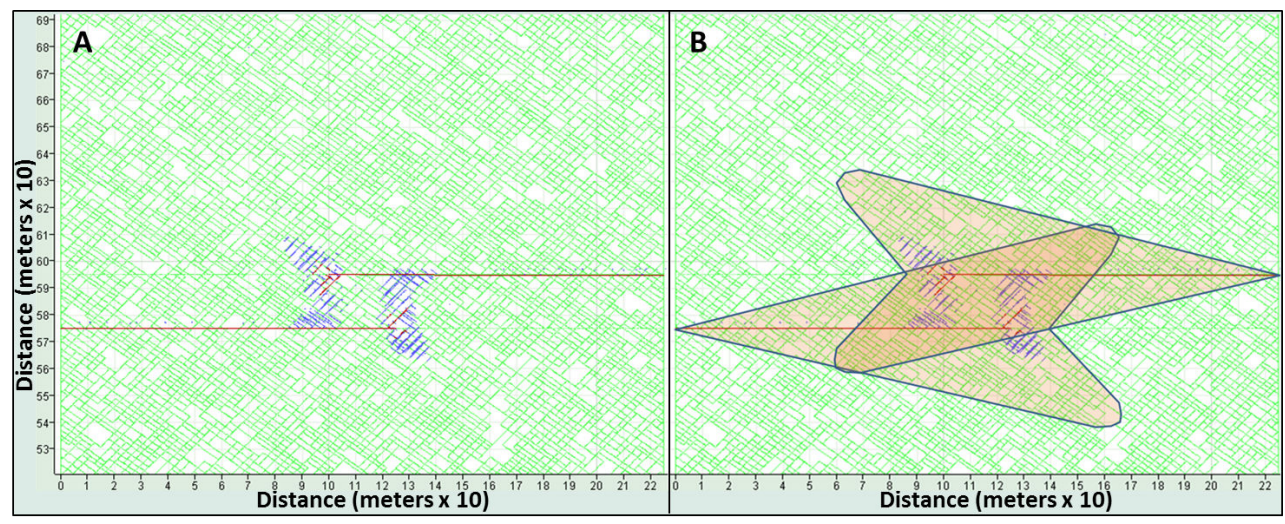

Figure 19. Natural fracture shear in blue from propagating hydraulic fractures Xf1 (from the left at $125 \mathrm{~m}$ ) and $X f 2$ (from the right at $125 \mathrm{~m}$ ) for a natural fracture friction of $25^{\circ}$. 


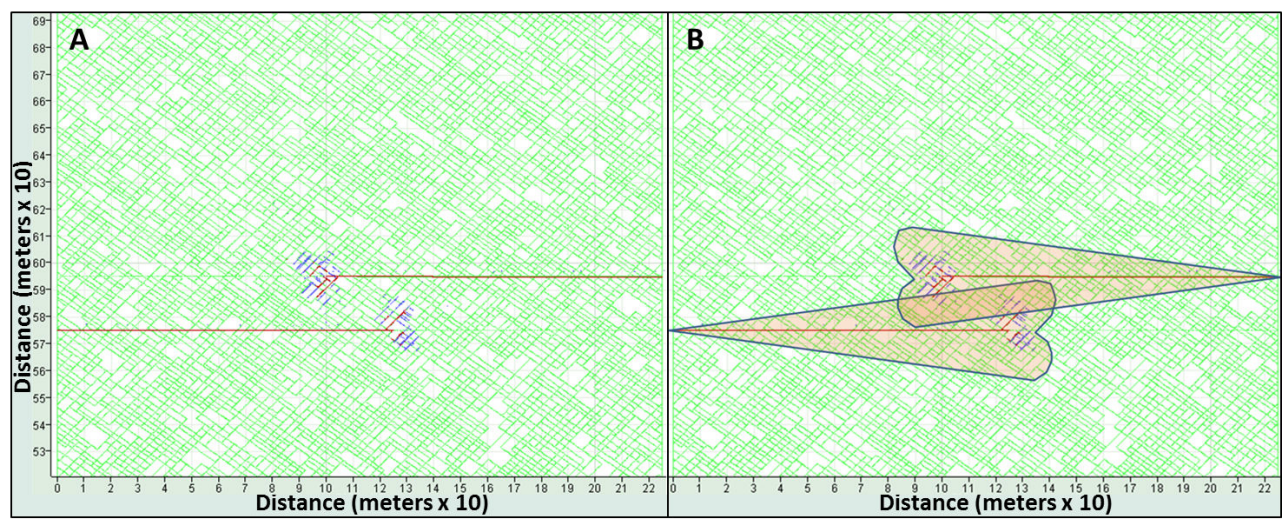

Figure 20. Natural fracture shear in blue from propagating hydraulic fractures $X f 1$ (from the left at $125 \mathrm{~m}$ ) and $X f 2$ (from the right at $125 \mathrm{~m}$ ) for a natural fracture friction of $35^{\circ}$.

\subsubsection{Observations for the ' $145^{\circ \prime}$ DFN and $20 m$ separation simulations}

The simulations were conducted such that hydraulic fracture Xf1 always had a fracture halflength of $125 \mathrm{~m}$ and 'snapshots' were taken for hydraulic fracture Xf2 half-lengths of $50 \mathrm{~m}, 75$, $100 \mathrm{~m}$, and $125 \mathrm{~m}$. The simulated wellbores that Xf1 and Xf2 propagated from were set at $225 \mathrm{~m}$ apart so that once Xf2 reached $100 \mathrm{~m}$ or longer, it overlapped hydraulic fracture Xf1.

The significant observations from the simulation results include:

- For the 20m separation cases shown, the greatest 'extra' natural fracture shear (shear beyond what would have occurred from two independent hydraulic fractures) occurred when Xf2 was $50 \mathrm{~m}$ in length. This was true for both natural fracture friction cases (Figures 13 and $14)$.

- As Xf2 grew beyond 50m in length, the 'extra' formation shear decreased and, most importantly, when Xf2 was $100 \mathrm{~m}$ or $125 \mathrm{~m}$ in length, there was a net loss of sheared natural fractures as compared to two independent hydraulic fractures.

- When Xf2 was 100m in length (so that the fracture tips from Xf1 and Xf2 just overlapped), the effect was a complete cancellation of natural fracture shear and a significant opening of natural fractures between $\mathrm{Xf} 1$ and $\mathrm{Xf} 2$ (likely allowing significant pressure communication) as shown in Figures 17 and 18.

- Once Xf2 exceeded $100 \mathrm{~m}$ in length, natural fracture shear re-occurred, though it was significantly reduced (Figures 19 and 20). Note that in Figure 19 (natural fracture friction of $25^{\circ}$ ), the hydraulic fractures blunted the sheared fractures coming from the tip of the other hydraulic fracture acting as a form of release surface preventing transmission of shear on the other side of the hydraulic fracture. 


\subsubsection{Shear results for the ' $145^{\circ \prime}$ DFN and other hydraulic fracture separations}

Figures 21 to 24 show a comparison of natural fracture shear for hydraulic fracture separations of $20 \mathrm{~m}, 35 \mathrm{~m}$, and $45 \mathrm{~m}$ for both natural fracture friction cases for Xf2 lengths of $75 \mathrm{~m}$ and $125 \mathrm{~m}$.

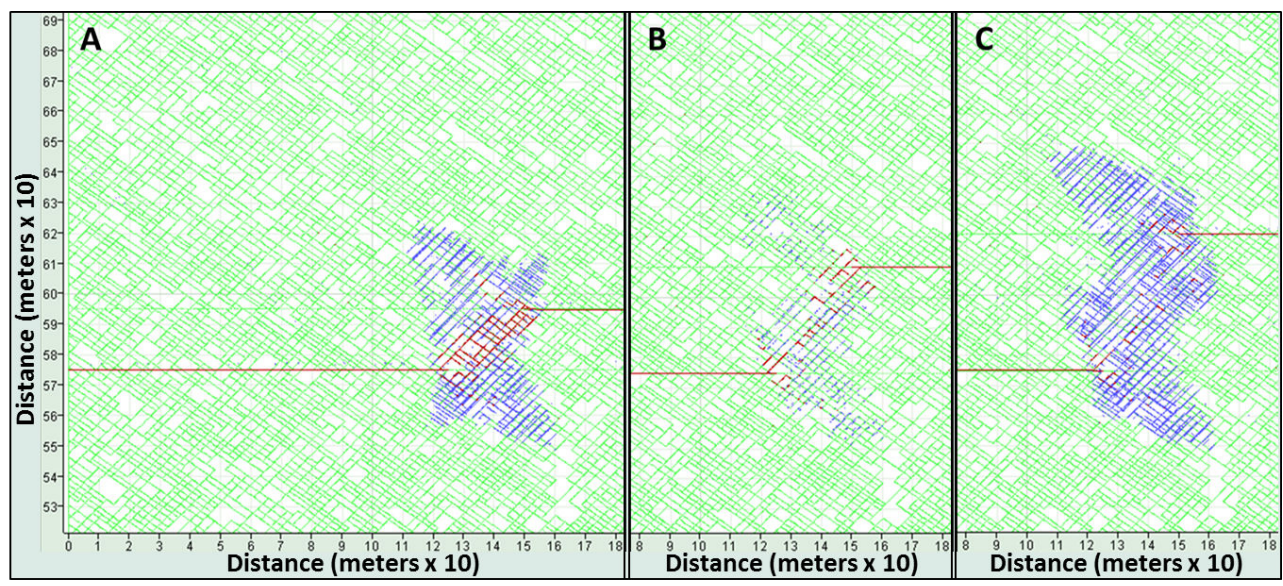

Figure 21. Natural fractures at shear as shown in blue for an Xf2 half-length of $75 \mathrm{~m}$ and natural fracture friction of $25^{\circ}$. Red represents open fractures. A) A $20 \mathrm{~m}$ hydraulic fracture separation; B) A $35 \mathrm{~m}$ separation; and C) A $45 \mathrm{~m}$ separation.

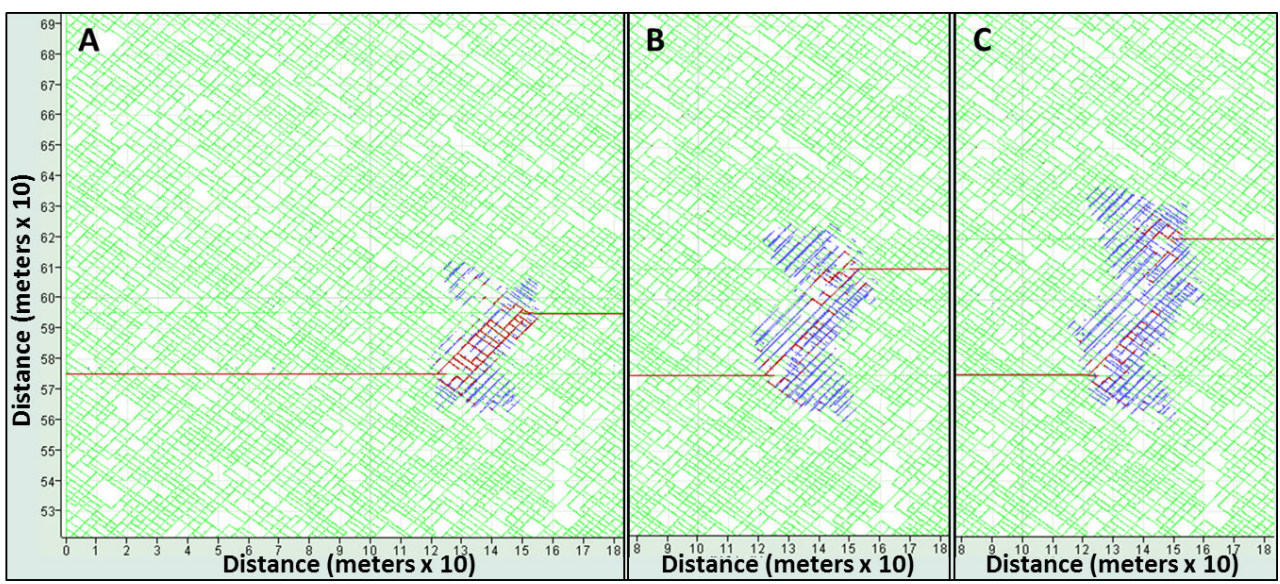

Figure 22. Natural fractures at shear as shown in blue for an Xf2 half-length of $75 \mathrm{~m}$ and natural fracture friction of $35^{\circ}$. A) A $20 \mathrm{~m}$ hydraulic fracture separation; B) A $35 \mathrm{~m}$ separation; and C) A $45 \mathrm{~m}$ separation. 


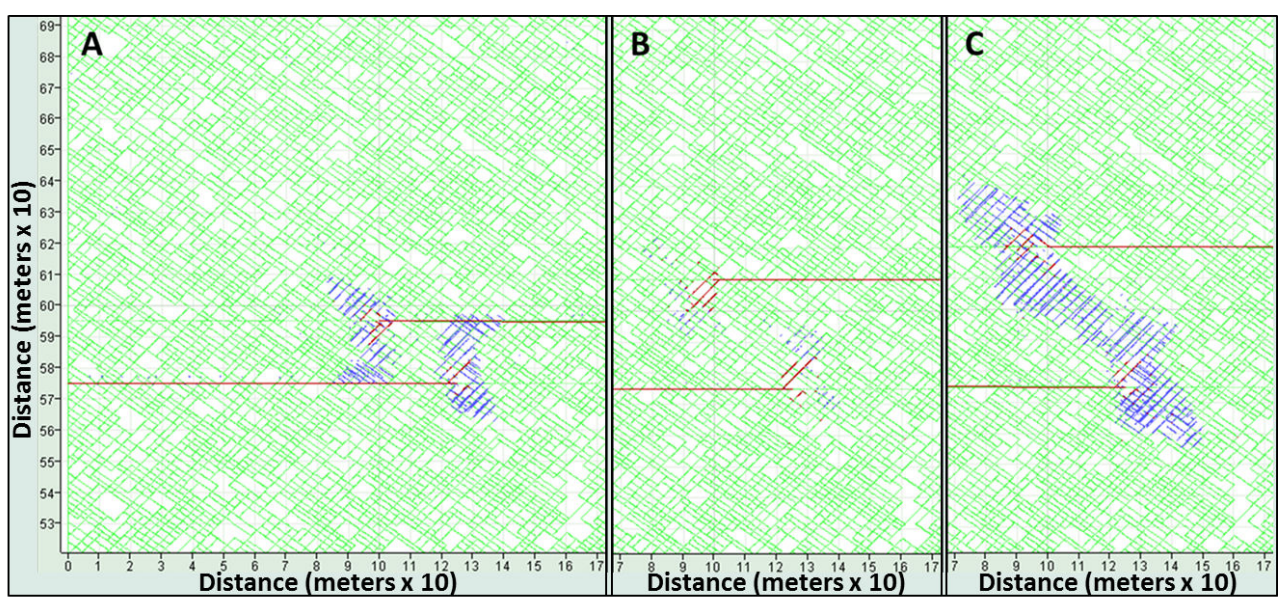

Figure 23. Natural fractures at shear as shown in blue for an $X f 2$ half-length of $125 \mathrm{~m}$ and natural fracture friction of $25^{\circ}$. A) A 20 m hydraulic fracture separation; B) A 35 m separation; and C) A 45 m separation

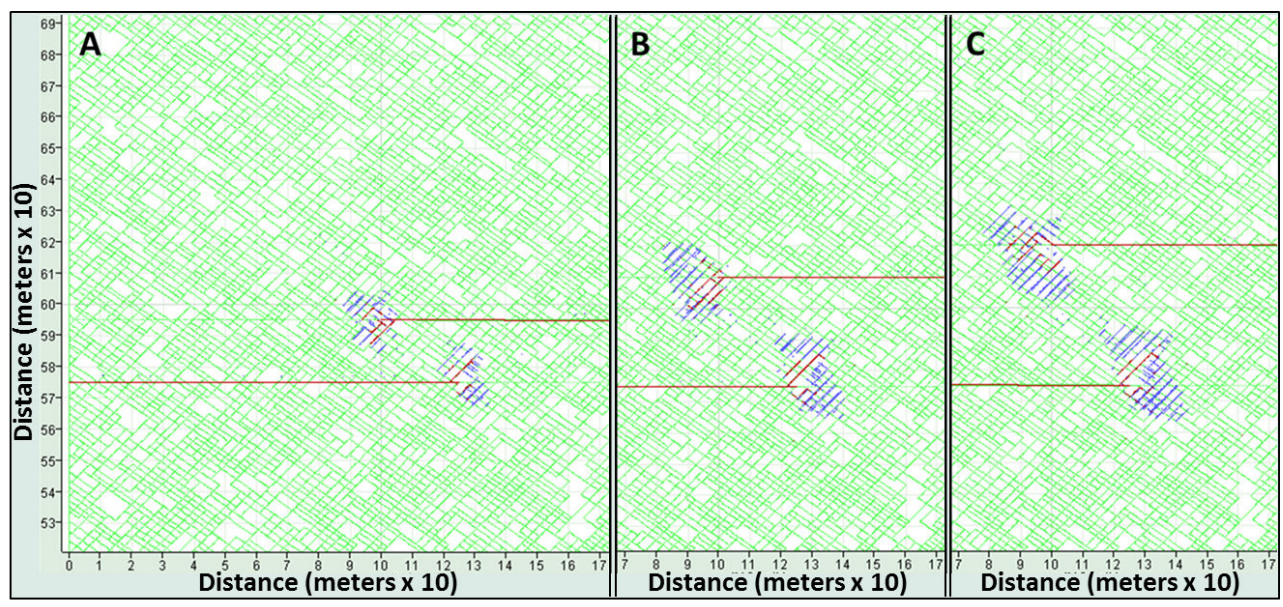

Figure 24. Natural fractures at shear as shown in blue for an $\mathrm{Xf2}$ half-length of $125 \mathrm{~m}$ and natural fracture friction of $35^{\circ}$. A) A 20 m hydraulic fracture separation; B) A 35 m separation; and C) A $45 \mathrm{~m}$ separation.

Figure 25 presents a graph of the cumulative length of natural fracture shear for the 30 simulations with the ' $145^{\circ \prime}$ DFN. 


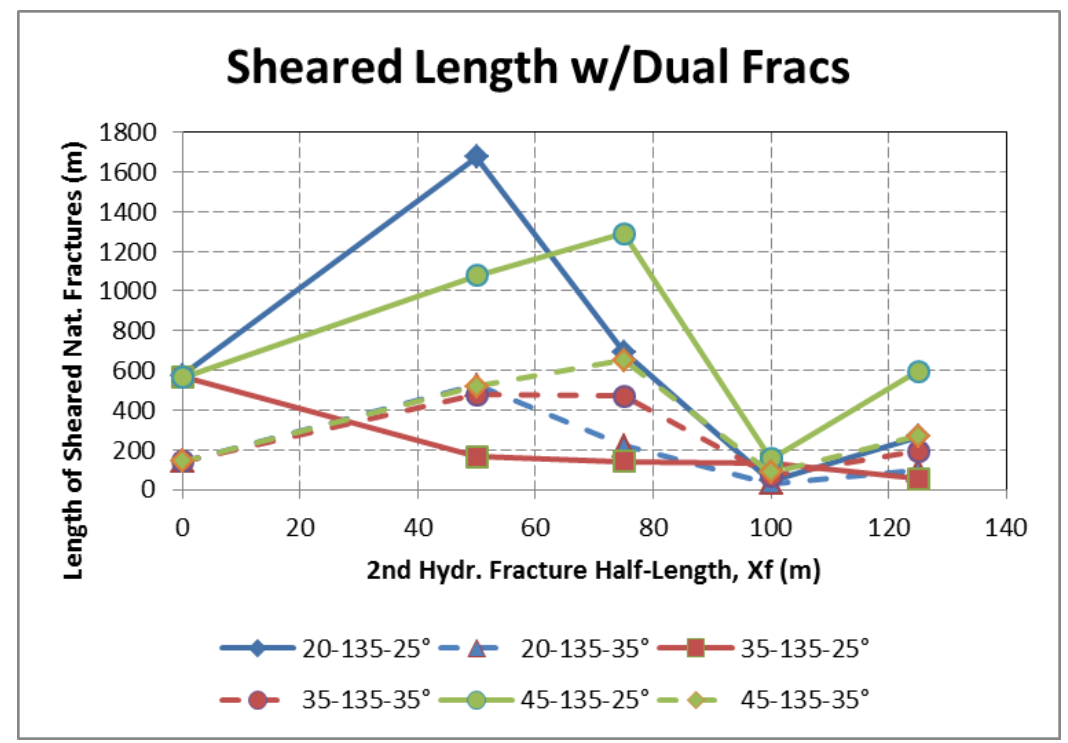

Figure 25. Graph of cumulative natural fracture shear length versus hydraulic fracture $X f 2$ half-length for separation cases $20 \mathrm{~m}, 30 \mathrm{~m}$, and $45 \mathrm{~m}$ for natural fracture friction of $25^{\circ}$ and $35^{\circ}$ for the ' $145^{\circ}$ DFN.

\subsubsection{Observations for the ' $145^{\circ \prime} \mathrm{DFN}$ dual hydraulic fracture simulations}

Within Figures 21 to 24, the simulation results for each of the three hydraulic fracture separation distances $(20 \mathrm{~m}, 35 \mathrm{~m}$, and $45 \mathrm{~m})$ are shown. Again, blue lines represent natural fractures at a shear condition at the moment the two hydraulic fractures are at their given half-length $(125 \mathrm{~m}$ for $\mathrm{Xf} 1$ and $75 \mathrm{~m}$ or $125 \mathrm{~m}$ for $\mathrm{Xf} 2$ ). Red lines represent open fractures (meaning there is no longer contact between the two sides of the fracture).

The significant observations from the simulation results include:

- Perhaps not surprisingly, the greatest total length of shear occurs for the $20 \mathrm{~m}$ separation distance (at an Xf2 half-length of 50m); however, most interesting is that the total length of shear for the $45 \mathrm{~m}$ separation distance is greater than that for the $35 \mathrm{~m}$ separation distance. This suggests that natural fracture shear created between two hydraulic fracture tips is both a function of the separation distance and the orientation of the natural fractures.

- The simulation results suggest that the Xf2 half-length at which the maximum induced length of natural fracture shear occurs is related to the hydraulic fracture separation. For the $20 \mathrm{~m}$ separation case, maximum shear occurred at Xf2 equal to $50 \mathrm{~m}$ while for the $45 \mathrm{~m}$ separation case, maximum shear occurred when the half-length of Xf2 was $75 \mathrm{~m}$.

- In all the cases, when the half-length of Xf2 was equal to $100 \mathrm{~m}$ (so that the tips of Xf1 and Xf2 just overlapped), natural fracture shear was at a minimum. 
- In all the cases, when the half-length of Xf2 grew to $125 \mathrm{~m}$, the cumulative length of natural fracture shear increased, but only modestly and significantly less than before the two hydraulic fractures overlapped. This suggests that overlapping hydraulic fractures do not enhance natural fracture shear but cause a net loss of shear relative to two independent hydraulic fractures.

- While for the $20 \mathrm{~m}$ and $45 \mathrm{~m}$ separation cases the effect of higher natural fracture friction was to significantly reduce the cumulative length of natural fracture shear (by $50 \%$ to $75 \%$ ), for the $35 \mathrm{~m}$ separation case the higher natural fracture friction resulted in greater cumulative natural fracture shear than the lower natural fracture friction case. While the full cause of this is not defined, a likely contributor is the ability of the rock mass in the low friction case to accommodate greater deformation without reaching the shear condition.

\subsubsection{Shear results for the ' $180^{\circ}$ ' DFN and $20 m$ hydraulic fracture separation}

Figures 26 and 27 show the natural fracture shear (in blue) for Xf2 half-length cases of 50m, $75,100 \mathrm{~m}$, and $125 \mathrm{~m}$ for the ' $180^{\circ}$ ' DFN with a $20 \mathrm{~m}$ separation distance and a natural fracture friction of $15^{\circ}$.

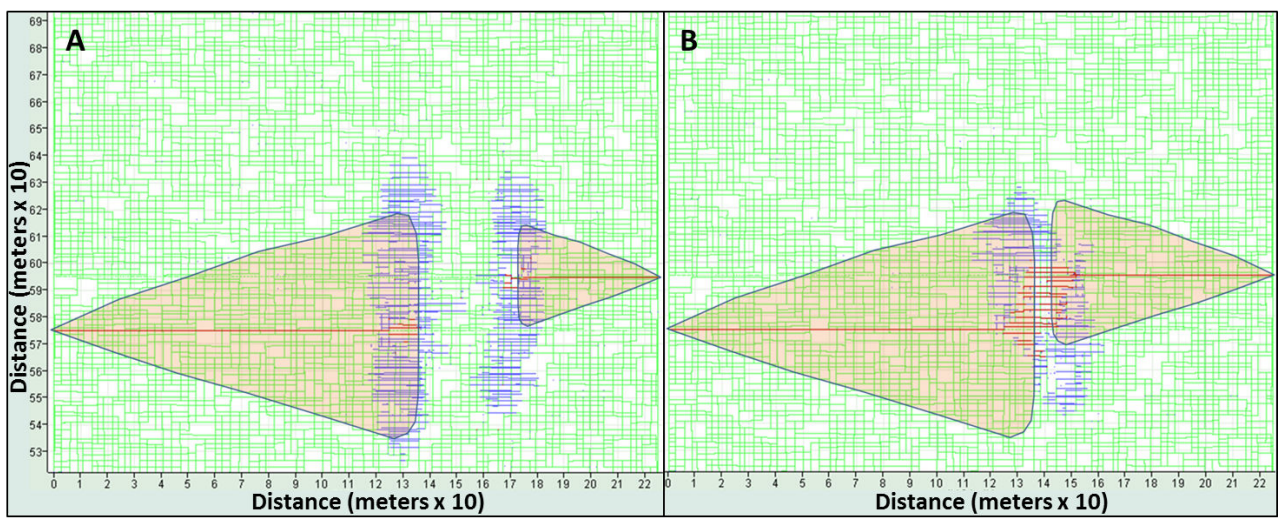

Figure 26. Natural fracture shear in blue from propagating hydraulic fractures $X f 1$ (from the left at $125 \mathrm{~m}$ ) and $X f 2$ (from the right) for a natural fracture friction of $15^{\circ}$ and $20 \mathrm{~m}$ hydraulic fracture separation. Red represents open fractures and shaded regions represent the expected shear area for two independent hydraulic fractures. A) Xf2 length equal to $50 \mathrm{~m}$; and B) $\mathrm{Xf2}$ length equal to $75 \mathrm{~m}$.

Similar in fashion to Figures 13 to 20 for the ' $145^{\circ}$ ' DFN, Figures 26 and 27 show that there is an increase in natural fracture shear over two independent hydraulic fractures when $\mathrm{Xf} 2$ is less than about $75 \mathrm{~m}$. Further, when Xf2 exceeds a half-length of more than $75 \mathrm{~m}$ (or, better, when the tip of $\mathrm{Xf}_{\mathrm{f} 2}$ is within $25 \mathrm{~m}$ of overlapping the tip of $\mathrm{Xf1}$ ), then the result is a net loss of natural fracture shear over two independent hydraulic fractures. 


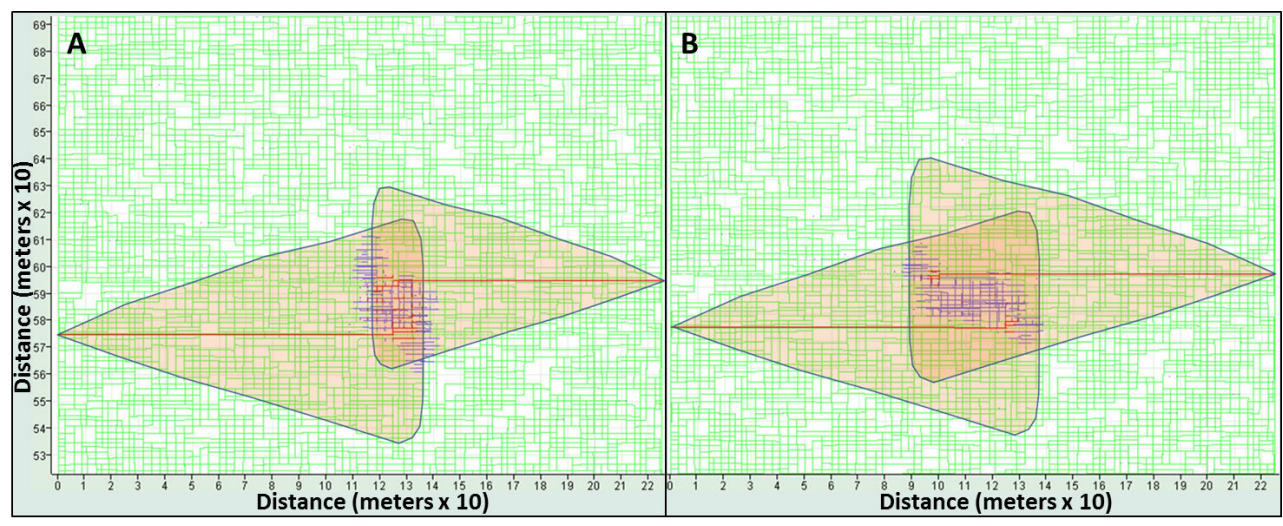

Figure 27. Natural fracture shear in blue from propagating hydraulic fractures $X f 1$ (from the left at $125 \mathrm{~m}$ ) and $X f 2$ (from the right) for a natural fracture friction of $15^{\circ}$ and $20 \mathrm{~m}$ hydraulic fracture separation. Red represents open fractures and shaded regions represent the expected shear area for two independent hydraulic fractures. A) Xf2 length equal to $100 \mathrm{~m}$; and $\mathrm{B}) \mathrm{Xf2}$ length equal to $125 \mathrm{~m}$.

Figures 28 to 31 show a comparison of natural fracture shear for hydraulic fracture separations of $20 \mathrm{~m}, 35 \mathrm{~m}$, and $45 \mathrm{~m}$ for both natural fracture friction cases $\left(15^{\circ}\right.$ and $\left.25^{\circ}\right)$ for Xf2 lengths of $75 \mathrm{~m}$ and $125 \mathrm{~m}$. Figure 32 shows a graph of the cumulative length of natural fracture shear versus Xf2 half-length for the $15^{\circ}$ and $25^{\circ}$ simulations (30 in total) for the ' $180^{\circ}$ ' DFN.

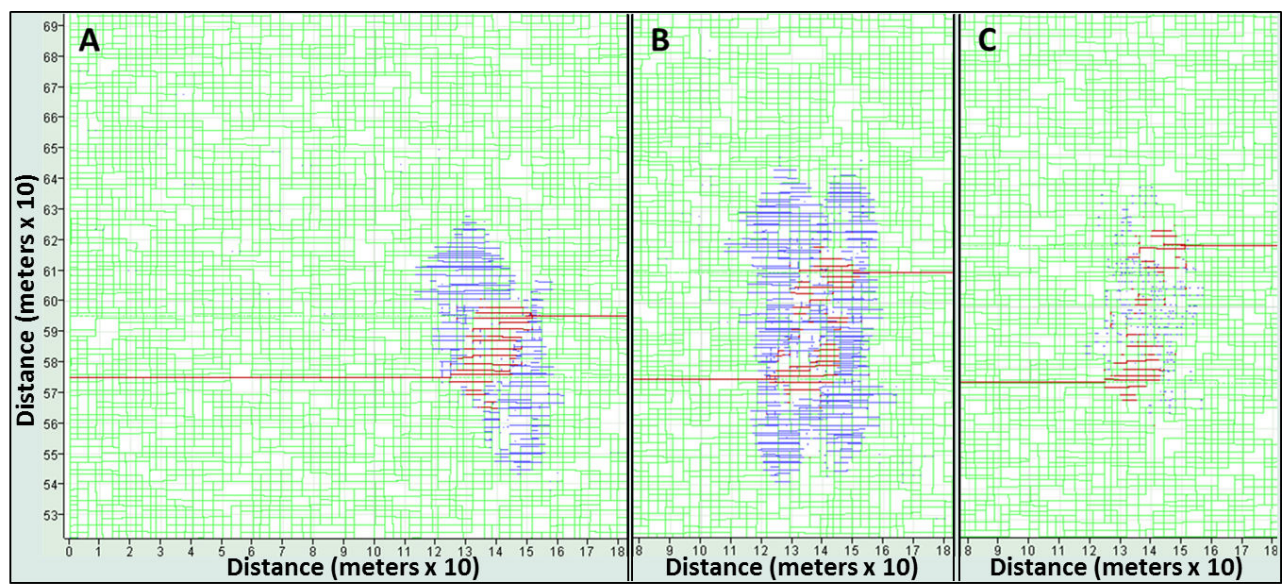

Figure 28. Natural fractures at shear (blue) for an Xf2 half-length of $75 \mathrm{~m}$ and natural fracture friction of $15^{\circ}$ for the ' $180^{\circ}$ ' DFN. Red represents open fractures. A) A 20 m hydraulic fracture separation; B) A 35m separation; and C) A 45m separation. 


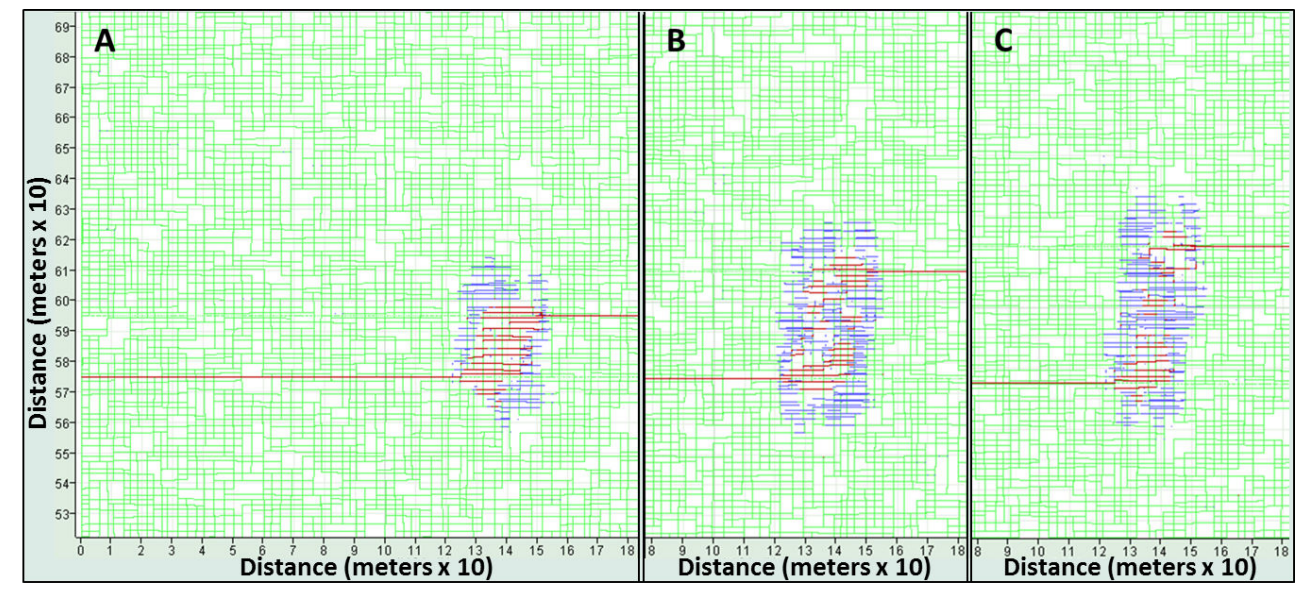

Figure 29. Natural fractures at shear (blue) for an Xf2 half-length of $75 \mathrm{~m}$ and natural fracture friction of $25^{\circ}$ for the ' $180^{\circ}$ ' DFN. Red represents open fractures. A) A 20 m hydraulic fracture separation; B) A 35m separation; and C) A 45m separation.

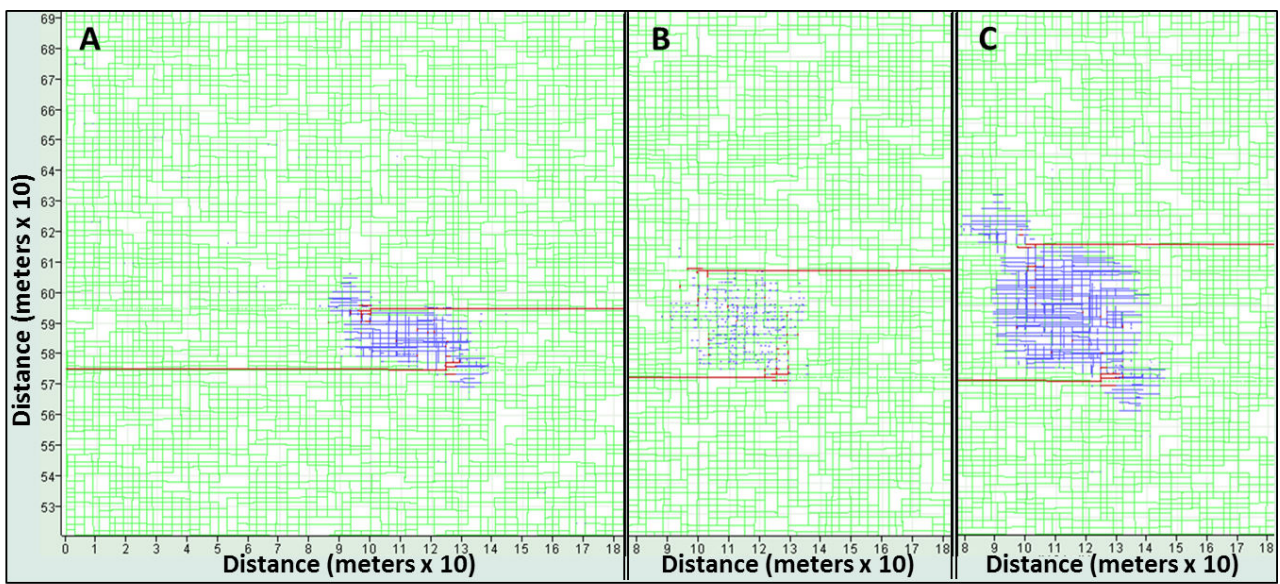

Figure 30. Natural fractures at shear (blue) for an Xf2 half-length of $125 \mathrm{~m}$ and natural fracture friction of $15^{\circ}$ for the ' $180^{\circ}$ ' DFN. Red represents open fractures. A) A $20 \mathrm{~m}$ hydraulic fracture separation; B) A 35m separation; and C) A 45m separation. 


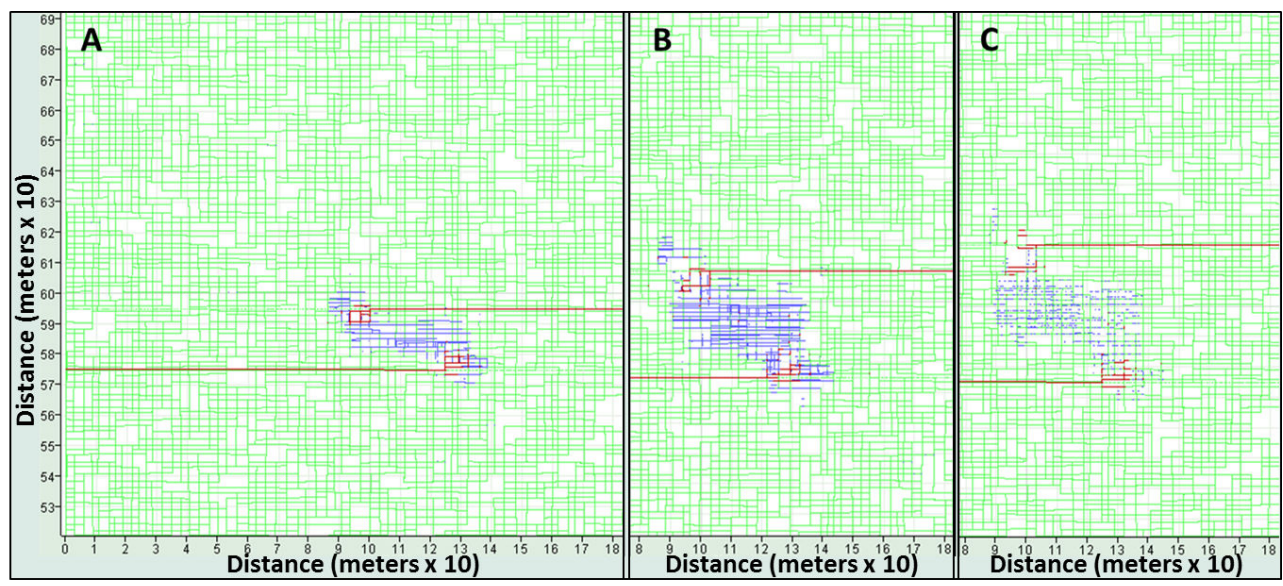

Figure 31. Natural fractures at shear (blue) for an Xf2 half-length of $125 \mathrm{~m}$ and natural fracture friction of $25^{\circ}$ for the ' $180^{\circ}$ ' DFN. Red represents open fractures. A) A 20 m hydraulic fracture separation; B) A 35m separation; and C) A 45m separation.

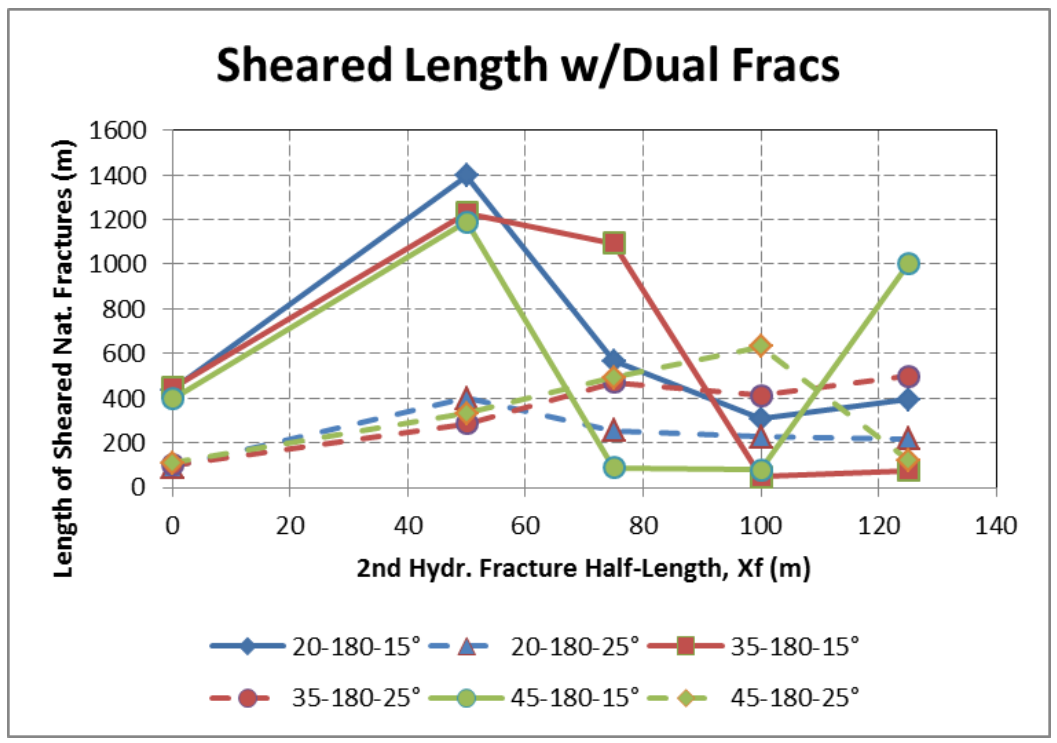

Figure 32. Graph of cumulative natural fracture shear length versus hydraulic fracture Xf2 half-length for separation cases $20 \mathrm{~m}, 30 \mathrm{~m}$, and $45 \mathrm{~m}$ for natural fracture friction of $15^{\circ}$ and $25^{\circ}$ for the ' $180^{\circ}$ DFN. 


\subsubsection{Observations for the ' $180^{\circ \prime} \mathrm{DFN}$ dual hydraulic fracture simulations}

Within Figures 28 to 31, the simulation results for each of the three hydraulic fracture separation distances (20m, 35m, and $45 \mathrm{~m}$ ) are shown for the ' $180^{\circ}$ ' DFN. Again, blue lines represent natural fractures at a shear condition at the moment the two hydraulic fractures are at their given half-length (125m for Xf1 and $75 \mathrm{~m}$ or $125 \mathrm{~m}$ for Xf2). Red lines represent open fractures (meaning there is no longer contact between the two sides of the fracture).

The significant observations from the simulation results include:

- As with the simulations for the ' $145^{\circ}$ ' DFN, the higher friction cases generally resulted in less total length of sheared natural fractures than the lower friction cases; however, when Xf2 was $100 \mathrm{~m}$ (so the tips of Xf1 and Xf2 just overlapped), the higher friction cases generally had more sheared length of natural fractures.

- For all three separation cases, the greatest total length of natural fracture shear occurred when the Xf2 half-length was 50m. As the separation distance increased between the hydraulic fractures, the total length of natural fracture shear became increasing sensitive to Xf2 half-length. For the $45 \mathrm{~m}$ separation case, the total length of natural fracture shear decreased by more than $90 \%$ between an Xf2 half-length of $50 \mathrm{~m}$ and $75 \mathrm{~m}$.

- For the ' $180^{\circ \prime} \mathrm{DFN}$, the cumulative length of natural fracture shear was not as sensitive at an Xf2 half-length of $100 \mathrm{~m}$ as was the ' $145^{\circ \prime}$ DFN. This, again, shows that the orientation of the natural fractures is important in creating natural fracture shear when two hydraulic fractures influence each other.

- As with the ' $145^{\circ}$ ' DFN, the amount of open fractures in the ' $180^{\circ \prime}$ DFN cases appeared to influence the amount of natural fracture shear. Further, open natural fractures will be more conductive and, likely, allow pressure communication between hydraulic fractures potentially causing screenout events.

\subsubsection{Shear results for the ' $180^{\circ \prime}$ DFN and altered in-situ stress}

Recall from Table 2 that a number of simulations were conducted with the ' $180^{\circ}$ ' DFN model wherein the in-situ stress field was altered. As shown in Table 2, the vertical stress Sv, maximum horizontal stress SHmax, and pore pressure were kept constant and the minimum horizontal stress was increased by $5.6 \mathrm{MPa}$, which resulted in near-isotropic horizontal stress conditions. Figures 33 and 34 show the sheared natural fractures for the $20 \mathrm{~m}$ separation case and natural fracture friction of $15^{\circ}$ and $25^{\circ}$ and with the revise in-situ stress. Figure 35 shows a graph of the length of natural fracture shear for the $25^{\circ}$ simulations from and Table 6 and initial and revised stresses.

\subsubsection{Observations for the ' $180^{\circ \prime}$ DFN dual fracture simulations with revised in-situ stress}

The significant observations from the simulation of the change in in-situ stress include: 


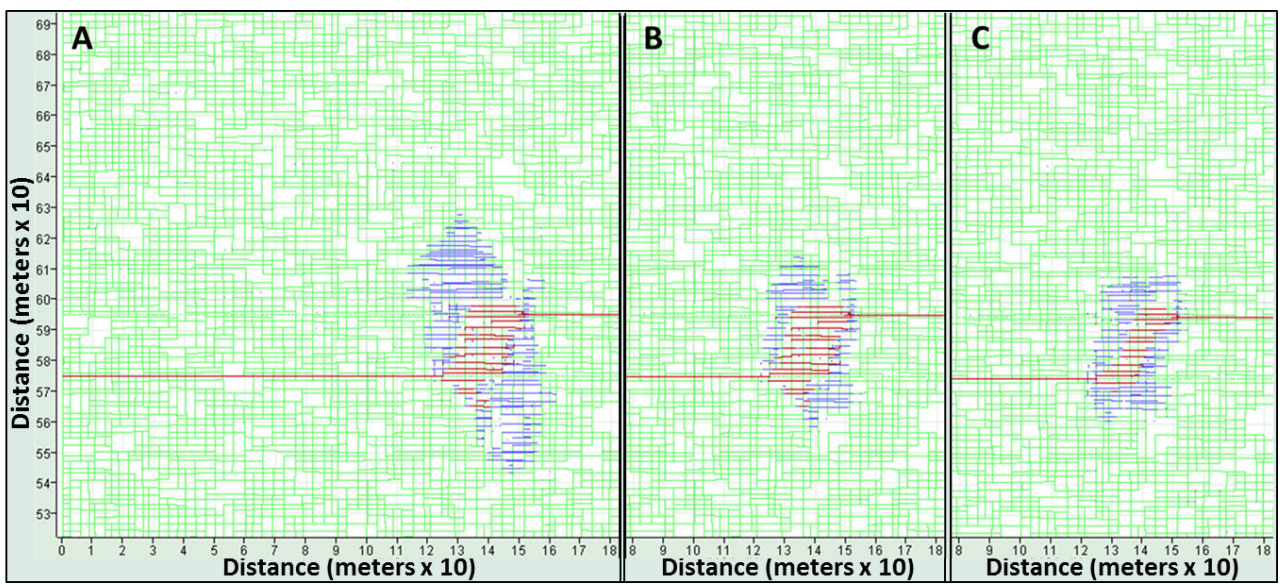

Figure 33. Natural fractures at shear (blue) for an Xf2 half-length of $75 \mathrm{~m}$ for the ' $180^{\circ \prime} \mathrm{DFN}$ at a $20 \mathrm{~m}$ separation. Red represents open fractures. A) $15^{\circ}$ natural fracture friction; B) $25^{\circ}$ fracture friction; and C) $25^{\circ}$ fracture friction and revised in-situ stress.

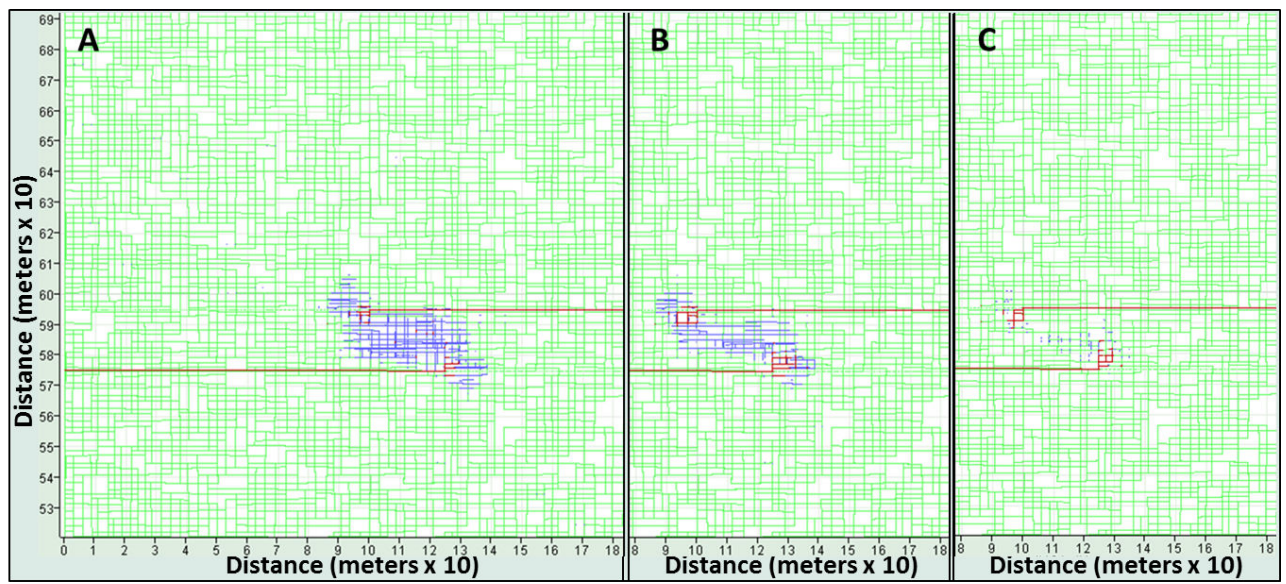

Figure 34. Natural fractures at shear (blue) for an Xf2 half-length of $125 \mathrm{~m}$ for the ' $180^{\circ \prime}$ DFN at a $20 \mathrm{~m}$ separation. Red represents open fractures. A) $15^{\circ}$ natural fracture friction; B) $25^{\circ}$ fracture friction; and C) $25^{\circ}$ fracture friction and revised in-situ stress. 


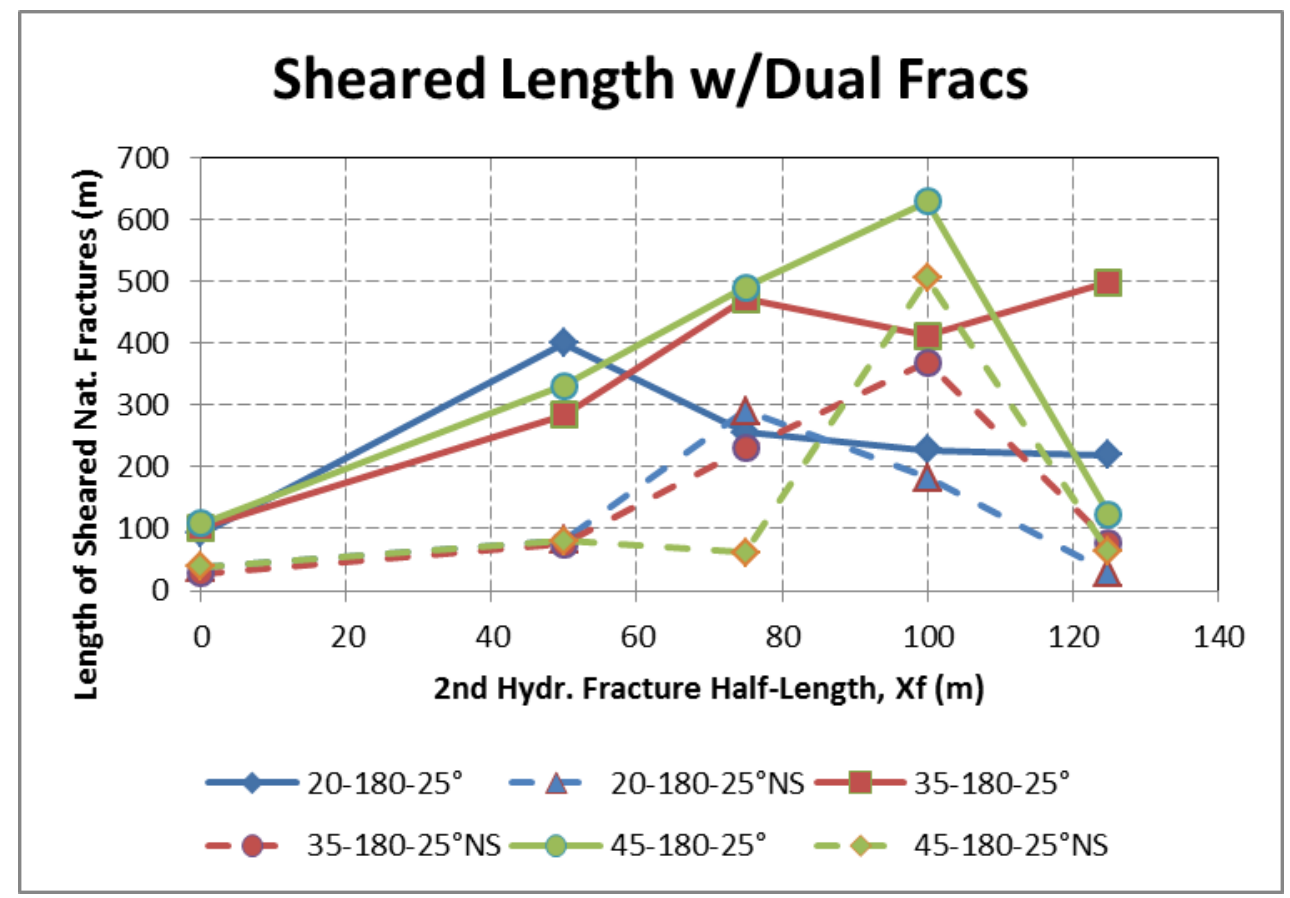

Figure 35. Graph of natural fracture shear length versus hydraulic fracture Xf2 half-length for separation cases $20 \mathrm{~m}, 30 \mathrm{~m}$, and $45 \mathrm{~m}$ for natural fracture friction of $25^{\circ}$ for the ' $180^{\circ \prime}$ DFN with the initial and revised in-situ stress (see Table 2).

- As shown in Figure 35, the maximum cumulative length of natural fracture shear occurred at the $45 \mathrm{~m}$ separation distance for either in-situ stress case.

- Clearly, moving towards more of an isotropic in-situ horizontal stress reduced the total length of natural fracture shear. Furthermore, the overall behavior also changed such that the maximum cumulative length of natural fracture shear occurred at $100 \mathrm{~m}$ (the point of tip-to-tip overlap) for the near-isotropic stress case.

- Particularly at larger separation distances (the $45 \mathrm{~m}$ separation case), the isotropic in-situ stress appeared to make the two hydraulic fractures cancel the shear from each other until the tips of Xf1 and Xf2 were close or overlapped.

- Perhaps even more so than the initial stress cases, the cumulative length of natural fracture shear when the tips of $X f 1$ and $X f 2$ overlapped (e.g., the $125 \mathrm{~m}$ Xf2 case) dropped to nearzero for the revised stress simulations. This suggests that, even with a revised in-situ stress field, overlapping the tips of hydraulic fractures from parallel wellbores creates a net loss of natural fracture shear. 


\section{Discussion}

The goal of the effort was to quantitatively consider the change in natural fracture shear (shear being analogous with microseismicity generation and the potential stimulation of the natural fractures providing increased production from the hydraulic fracture) for multi-well completions. It is commonly believed that by configuring the geometry and injection behavior from parallel wellbores (e.g., simultaneous fracturing, zipper-fracs, and modified zipper-fracs), shear of the natural fractures can be enhanced (thereby increasing production).

During the evaluations presented in this paper, the following parameter effects were considered:

1. Fracture network orientation (i.e., the ' $180^{\circ \prime} \mathrm{DFN}$ and the ' $145^{\circ}$ ' DFN);

2. Natural fracture friction angle $\left(15^{\circ}\right.$ and $25^{\circ}$ for the ${ }^{\prime} 180^{\circ}$ ' DFN and $25^{\circ}$ and $35^{\circ}$ for the ' $145^{\circ}$ DFN);

3. Hydraulic fracture separation (offset between injection points) from $20 \mathrm{~m}$ to $45 \mathrm{~m}$;

4. Hydraulic fracture half-length from the second wellbore (Xf2 helf-lengths of $50 \mathrm{~m}$ to $125 \mathrm{~m}$ ); and

5. In-situ stress (from a horizontal stress ratio - SHmax/Shmin - of 1.18 to a ratio of 1.03).

\subsection{Observations on the influence of fracture network}

As shown in Figures 6 and 8, the natural fracture shear pattern coming off the tip of a propagating hydraulic fracture depends upon the orientation and nature of the natural fracture system. For the ' $180^{\circ}$ ' DFN, natural fracture shear extended a bit beyond the hydraulic fracture tip, but mainly lay in a symmetrical pattern perpendicular to the direction of hydraulic fracture propagation. In contrast, for the ' $145^{\circ \prime} \mathrm{DFN}$, the natural fracture shear pattern was asymmetric and lead the tip of the propagating hydraulic fracture. Clearly as observed in previous publications (Nagel et al. 2011a), interpreting microseismic event locations cannot be done without consideration of the general orientation of the natural fracture pattern.

The natural fracture pattern also plays a role in the amount of natural fracture shear (and, by analogy, the number of microseismic events). For the same natural fracture friction (and same in-situ stress), the total area of natural fracture shear for the ' $180^{\circ}$ ' DFN was only $42 \%$ of that for the ' $145^{\circ}$ ' DFN (2220 ${ }^{2}$ versus $\left.5250 \mathrm{~m}^{2}\right)$. However, as shown in the graphs in Figures 25 and 32 , the overall trends in the cumulative length of natural fracture shear from dual hydraulic fractures was similar (with the exception of the $35 \mathrm{~m}$ spacing for the $145^{\circ}$ ' DFN in which natural fracture shear was very low).

\subsection{Observations on the influence of natural fracture friction}

As evident from the figures of natural fracture shear and the quantitative results in Figures 25 and 32, natural fracture friction plays a significant role in determining the amount of natural fracture shear (and, by analogy, the number of microseismic events). The influence of natural 
fracture friction also depends upon the underlying natural fracture pattern (and stress ratio). The area of shear generated for the ' $180^{\circ}$ ' DFN at a friction angle of $15^{\circ}$ was nearly equal to the area of natural fracture shear for the ' $145^{\circ}$ ' DFN at a friction angle of $25^{\circ}\left(5740 \mathrm{~m}^{2}\right.$ versus $\left.5250 \mathrm{~m}^{2}\right)$.

Less so for the ' $145^{\circ \prime}$ DFN and more so for the ' $180^{\circ}$ ' DFN, the higher fracture friction tended to push the point of maximum total length of natural fracture shear towards longer Xf2 halflengths; however, these longer half-lengths also represented conditions when there was a net loss of natural fracture shear for two dual hydraulic fractures over two equivalent independent hydraulic fractures.

\subsection{Observations on the influence of hydraulic fracture separation distance}

Figures 25 and 32 suggest that hydraulic fracture separation did not significantly affect the maximum total length of natural fracture shear (more so for the ' $180^{\circ}$ ' DFN and less so for the ' $145^{\circ}$ DFN). However, the influence of separation spacing was more apparent when the Xf2 half-length was $100 \mathrm{~m}$ or longer.

Though Figures 25 and 32 may suggest a somewhat limited influence of hydraulic fracture spacing, this is clearly not the whole picture. As shown in Figures 9 through 12 in particular, and somewhat in Figures 13 through 20, the critical issues for hydraulic fracture separation are to: 1) shear as much total formation as possible; and 2) not cause a net loss of natural fracture shear by placing hydraulic fractures too close. Figure 10 shows that at a $45 \mathrm{~m}$ hydraulic fracture separation distance (for dual, 125m-long hydraulic fractures and a natural fracture friction angle of $15^{\circ}$ ) the shear area from the two hydraulic fractures still overlapped (when the hydraulic fractures act independently). In contrast, Figure 12 shows that a $45 \mathrm{~m}$ separation distance may be too much when natural fracture friction angle is $25^{\circ}$.

\subsection{Observations on the influence of hydraulic fracture $X f 2$ half-length}

The simulation results (especially Figures 25 and 32) show that the amount of natural fracture shear is significantly influenced by the half-length of the Xf2 hydraulic fracture in a dual fracture configuration. The overall trend of the results is that keeping the half-length of Xf2 small enough to prevent the tip of Xf2 from getting closer than $25 \mathrm{~m}$ to the tip of $\mathrm{Xf1}$ (that is, no overlap of the hydraulic fractures) creates the maximum total length of natural fracture shear. Further, as shown in Figures 9 through 12, keeping the half-length of Xf2 small enough may also cause a net increase in natural fracture shear (over that from two independent hydraulic fractures), which is the goal of a dual hydraulic fracture configuration.

\section{Conclusions}

- As natural fracture orientation (relative to the orientation of a hydraulic fracture) significantly influences the amount and location of natural fracture shear, multi-well completion 
optimization (wherein the goal is to maximize natural fracture shear, i.e., maximize 'complexity') requires the evaluation and consideration of natural fracture orientation.

- As natural fracture friction controls the depth and amount of natural fracture shear, multiwell completion optimization requires the evaluation and consideration of natural fracture friction properties.

- The optimum hydraulic fracture separation distance for multi-well completions (i.e, the separation of hydraulic fractures along their respective wellbores) must be determined in consideration of natural fracture properties (e.g., orientation and friction properties) and the in-situ stress ratio.

- For multi-well completion schemes, the design length of the second hydraulic fracture (Xf2) should be kept less than the point of overlap with the first hydraulic fracture (Xf1) and be optimized in conjunction with the hydraulic fracture separation distance.

- Overall, the simulation results presented suggest that there is the potential for only modest improvements in stimulation complexity from the modified zipper-frac completion scheme while the potential for well-to-well communication (and possible screenout conditions) increases.

\section{Author details}

N. Nagel, F. Zhang, M. Sanchez-Nagel and B. Lee

*Address all correspondence to: nnagel@itascahouston.com

Itasca Houston, Inc., USA

\section{References}

[1] Agarwal, K, Mayerhofer, M. J, \& Warpinski, N. R. (2012). Impact of Geomechanics on Microseismicity", Paper SPE 152835 presented at the SPE/EAGE European Unconventional Resources Conference and Exhibition, Vienna, Austria, March., 20-22.

[2] Clover Global SolutionsLP, (2012). The Seven Major U.S. Shale Plays", http://c1wsolutions.wordpress.com/2012/09/13/the-seven-major-u-s-shale-plays

[3] Ground Water Protection Council and ALL Consulting(2009). Modern Shale Gas Development in the United States: A Primer", prepared for the US DOE, Office of Fossil Energy, DE-FGNT15444., 26-04. 
[4] King, G. E. (2010). Thirty Years of Gas Shale Fracturing: What Have We Learned?", Paper SPE 133456 presented at the SPE Annual Technical Conference and Exhibition, Florence, Italy, September., 19-22.

[5] Nagel, N, \& Sanchez-nagel, M. (2011). Stress Shadowing and Microseismic Events: A Numerical Evaluation", Paper SPE 147363 presented at the SPE Annual Technical Conference and Exhibition, Denver, Colorado, USA, 30 October-2 November.

[6] Nagel, N, Damjanac, B, Garcia, X, \& Sanchez-nagel, M. (2011b). Discrete Element Hydraulic Fracture Modeling- Evaluating Changes in Natural Fracture Aperture and Transmissivity", Paper SPE 148957 presented at the Canadian Unconventional Resources Conference, Calgary, Alberta, Canada, November., 15-17.

[7] Nagel, N, Gil, I, Sanchez-nagel, M, \& Damjanac, B. (2011a). Simulating Hydraulic Fracturing in Real Fractured Rock- Overcoming the Limits of Pseudo3D Models", Paper SPE 140480 presented at the SPE Hydraulic Fracturing Technology Conference and Exhibition, The Woodlands, Texas, USA, January., 24-26.

[8] Nagel, N, Sanchez-nagel, M, \& Lee, B. T. (2012a). Gas Shale Hydraulic Fracturing: A Numerical Evaluation of the Effect of Geomechanical Parameters", Paper SPE 152192 presented at the SPE Hydraulic Fracturing Technology Conference and Exhibition, The Woodlands, Texas, USA, February., 6-8.

[9] Nagel, N. B, Garcia, X, Lee, B, \& Sanchez-nagel, M. (2012d). Hydraulic Fracturing Optimization for Unconventional Reservoirs- The Critical Role of the Mechanical Properties of the Natural Fracture Network", Paper SPE 161934 presented at the SPE Canadian Unconventional Resources Conference, Calgary, Alberta, Canada, 30 October- 1 November.

[10] Nagel, N. B, Sanchez-nagel, M, Zhang, F, Garcia, X, \& Lee, B. (2013). Coupled Numerical Evaluations of the Geomechanical Interactions Between a Hydrualic Fracture Stimulation and a Natural Fracture System in Shale Formations", Rock Mechanics and Rock Engineering, pending publication.

[11] Nagel, N. B, Sanchez-nagel, M, Garcia, X, \& Lee, B. (2012b). A Numerical Evaluation of the Geomechanical Interactions Between a Hydraulic Fracture Stimulation and a Natural Fracture System", ARMA presented at the 46th Rock Mechanics / Geomechanics Symposium, Chicago, Illinois, 24-27 June., 12-287.

[12] Nagel, N. B, Sanchez-nagel, M, Garcia, X, \& Lee, B. SRV": A Numerical Investigation of "Wet" vs. "Dry" Microseismicity During Hydraulic Fracturing", Paper SPE 159791 presented the SPE Annual Technical Conference and Exhibition held in San Antonio, Texas, USA, October., 8-10.

[13] Sneddon, I. N. (1946). The Distribution of Stress in the Neighbourhood of a Crack in an Elastic Solid", Proc. R. Soc. London, Ser. A. , 195, 229-260. 
[14] U.S. Energy Information Administration, 2012, "Annual Energy Outlook 2012 Early Release Overview", U.S. Dept. of Energy, Washington D.C., USA, www.eia.gov

[15] U.S. Energy Information Administration, 2013, "Annual Energy Outlook 2013 Early Release Overview", U.S. Dept. of Energy, Washington D.C., USA, www.eia.gov 